\title{
Nonenzymatic Reactions above Phospholipid Surfaces of Biological Membranes: Reactivity of Phospholipids and Their Oxidation Derivatives
}

\author{
Christian Solís-Calero, ${ }^{1,2}$ Joaquín Ortega-Castro, ${ }^{1,2}$ Juan Frau, ${ }^{1,2}$ and Francisco Muñoz ${ }^{1,2}$ \\ ${ }^{1}$ Institut d'Investigació en Ciències de la Salut (IUNICS), Departament de Química, Universitat de les Illes Balears, \\ 07122 Palma de Mallorca, Spain \\ ${ }^{2}$ Instituto de Investigación Sanitaria de Palma, 07010 Palma, Spain
}

Correspondence should be addressed to Joaquín Ortega-Castro; joaquin.castro@uib.es

Received 16 December 2014; Revised 24 March 2015; Accepted 25 March 2015

Academic Editor: Luciano Pirola

Copyright (C) 2015 Christian Solís-Calero et al. This is an open access article distributed under the Creative Commons Attribution License, which permits unrestricted use, distribution, and reproduction in any medium, provided the original work is properly cited.

\begin{abstract}
Phospholipids play multiple and essential roles in cells, as components of biological membranes. Although phospholipid bilayers provide the supporting matrix and surface for many enzymatic reactions, their inherent reactivity and possible catalytic role have not been highlighted. As other biomolecules, phospholipids are frequent targets of nonenzymatic modifications by reactive substances including oxidants and glycating agents which conduct to the formation of advanced lipoxidation end products (ALEs) and advanced glycation end products (AGEs). There are some theoretical studies about the mechanisms of reactions related to these processes on phosphatidylethanolamine surfaces, which hypothesize that cell membrane phospholipids surface environment could enhance some reactions through a catalyst effect. On the other hand, the phospholipid bilayers are susceptible to oxidative damage by oxidant agents as reactive oxygen species (ROS). Molecular dynamics simulations performed on phospholipid bilayers models, which include modified phospholipids by these reactions and subsequent reactions that conduct to formation of ALEs and AGEs, have revealed changes in the molecular interactions and biophysical properties of these bilayers as consequence of these reactions. Then, more studies are desirable which could correlate the biophysics of modified phospholipids with metabolism in processes such as aging and diseases such as diabetes, atherosclerosis, and Alzheimer's disease.
\end{abstract}

\section{Introduction}

Biological membranes play key roles in cell life, acting as permeability barriers and constituting privileged sites of communication between the inside and the outside of cells $[1,2]$. The importance of membranes for life is reflected in the genomes, where around one-third of the coded information corresponds to membrane proteins [3]. The main structural element of biological membranes is a lipid bilayer, having other components, such as proteins, sterols, and peptides, either intercalated into or loosely attached to it [4]. This lipid bilayer has as primary role to define the permeability barrier of cells and organelles, having the hydrophobic domain of their lipid components oriented inward and shielded from water and their hydrophilic domain exposed and interacting with the aqueous environment [5]. This bilayer provides also the supporting matrix and surface for many enzymatic reactions, participating in signal transduction and providing precursors for signaling processes and macromolecular synthesis.

Membrane lipid composition can vary dramatically across the three domains of life and even within single organisms [6]. In eukaryotic cells, phospholipids are the predominant membrane lipids (Scheme 1), phosphatidylcholine (PC) and phosphatidylethanolamine (PE) represent the 60\%$85 \%$ of the phospholipid fraction, while the fraction of other phospholipids depends on the cell membrane and even on animal species $[7,8]$. The distribution of phospholipids is asymmetric across the bilayer; nearly all anionic lipids in eukaryotic cells face the cytoplasm, whereas most lipids with large glycosylated headgroups are exposed to the extracellular environment. The chemical composition of the bilayer affects 


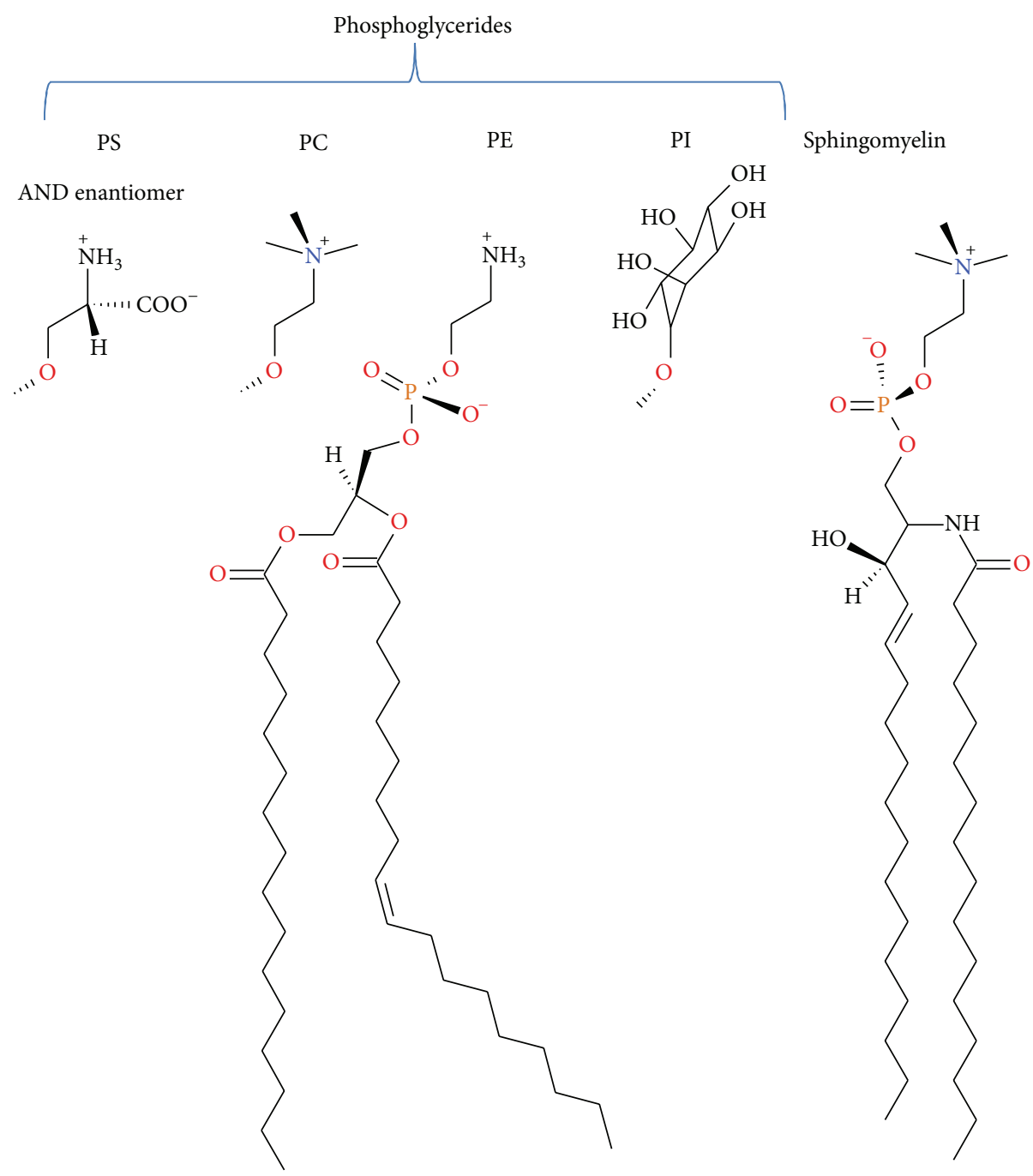

SCHEME 1: Structure of some phospholipids components of biological membranes (PS: phosphatidylserine, PC: phosphatidylcholine, PE: phosphatidylethanolamine, and PI: phosphatidylinositol).

its mechanical properties and, conversely, the application of forces to the membrane can alter its chemical composition [9]. Phospholipids also serve as sources of arachidonic acid and other polyunsaturated fatty acids, which can be metabolized by oxygenase enzymes leading to the formation of various lipid mediators that regulate a variety of biological functions. Their nonenzymatic modification by lipid peroxidation and glycation could conduct to the formation of advanced lipoxidation end products (ALEs) and advanced glycation end products (AGEs). These modifications introduce changes in cell membrane physicochemical and biological properties and could be accumulated during aging and diabetes [7].

Evolution is very economical and it could use some cell components with an apparent main function in order to be useful for other purposes [10]. It is very known that proteins have had diversification of their functions in the course of evolution as a response to different environmental changes [11-13]; RNA molecules also have had different evolutionary developments [14] and although it is not yet found in nature, DNA has been shown to be able to catalyse transesterification reactions, in the same way of ribozymes and protein enzymes $[15,16]$. As consequence of changes in these gene products, some ligands also have acquired diverse biological roles over the course of evolution $[17,18]$, and it is possible to hypothesize that other biological compounds could also diversify its functions. Phospholipids organized as a bilayer have as primary function to constitute a permeability barrier, being involved in a wide range of processes which explains the need for diversity in their structures. However, an inherent catalytic activity for phospholipids has not been suggested until few years ago [19-21], despite the charged and polar functional groups of the phospholipids heads which could act as proton donors and acceptors and the special dielectric medium constituted by the membrane/water interface.

Theoretical chemistry methods provide an atomistic-level description of the molecular systems, in a resolution that cannot be obtained experimentally, but their application in systems as biological membranes, which are enormously complex in terms of both structure and their dynamical properties, demands high computational power. In these 
TABLE 1: Theoretical studies about reactivity on phospholipid surfaces at DFT level of calculus.

\begin{tabular}{|c|c|c|c|}
\hline Studied reaction & Limited step & $\begin{array}{c}\text { Calculated } \\
\text { activation energy } \\
\left(\mathrm{Kcal} \mathrm{mol}^{-1}\right)\end{array}$ & Reference \\
\hline Decomposition of hydrogen peroxide & $\begin{array}{l}\text { Formation of an intermediate hydrogen } \\
\text { trioxide }\end{array}$ & 8.76 & {$[20]$} \\
\hline $\begin{array}{l}\text { Schiff base formation between PE and } \\
\text { acetaldehyde }\end{array}$ & $\begin{array}{l}\text { Dehydration of carbinolamine } \\
\text { intermediate }\end{array}$ & 13.08 & {$[19]$} \\
\hline $\begin{array}{l}\text { Amadori rearrangement from } \\
\text { PE-D-erythrose Schiff base }\end{array}$ & Formation of a 1,2-enaminol intermediate & 16.78 & [22] \\
\hline $\begin{array}{l}\text { Carboxymethyl-PE formation from } \\
\text { reaction between glyoxal and PE }\end{array}$ & $\begin{array}{l}\text { Dehydration of Carbino-diol-amine } \\
\text { intermediate }\end{array}$ & 15.41 & [23] \\
\hline $\begin{array}{l}\text { Reaction of aminoguanidine with } \\
\text { dicarbonyl-PE product }\end{array}$ & $\begin{array}{l}\text { Dehydration of an aminoguanidine } \\
\text { adduct }\end{array}$ & - & {$[24]$} \\
\hline
\end{tabular}

cases, it is necessary to generate models of which nature and size depend on the studied property and the used level of calculus. By theoretical analysis, biological membranes properties have been mostly studied employing molecular mechanics-based methods and compared to first-principles computational studies [32-35]. There were only few studies using density functional theory (DFT) methods [36-38] but using cluster models for studying conformational properties generally. Our group at first obtained a mechanism for nonenzymatic reactions on a model of a phospholipid surface at DFT level of theory $[19,20,22-24]$ (Table 1). The developed model of PE surface is a periodic model which has in its unit cell two PE molecules according to the studied reaction and a sufficient number of water molecules for forming hydrogenbond networks (Figure 1). The procedure for obtaining the mechanisms of reactions included calculating transition states and describing energetic and geometric changes along the reaction coordinates, features difficult to describe based on experimental results only. Periodic boundary conditions were fundamental for these calculations, making it possible to model a phospholipids surface, studying its reactivity at the DFT level, and allowing the equivalent transfer of protons between unit cell images due to their boundary translation invariance property (Scheme 2). This methodology has been applied extensively in theoretical modelling of solid-state materials [39, 40] and little to biological molecules [41].

Other theoretical methods used for studying lipid bilayer systems are classical molecular dynamics simulations, which are able to provide more complete description of the dynamics and energetics of membranes with high spatial-temporal resolution [4, 42, 43]. In these methods, the positions of individual atoms in the system are followed by numerically solving classical equations of motion. Potential energy of the interactions is described in the form of force field, based on both empirical and quantum chemical data [43, 44]. Since molecular dynamics simulations are based on models, the results of such simulations are required to be validated by experimental data; a good agreement between them makes it reasonable to trust the basic models and use the simulations to explain experimental results and extend the analysis to phenomena that cannot be studied by experiments $[43,45]$. Despite that, these methods have some limitations, originated by uncertainties in the chosen force field, and the short

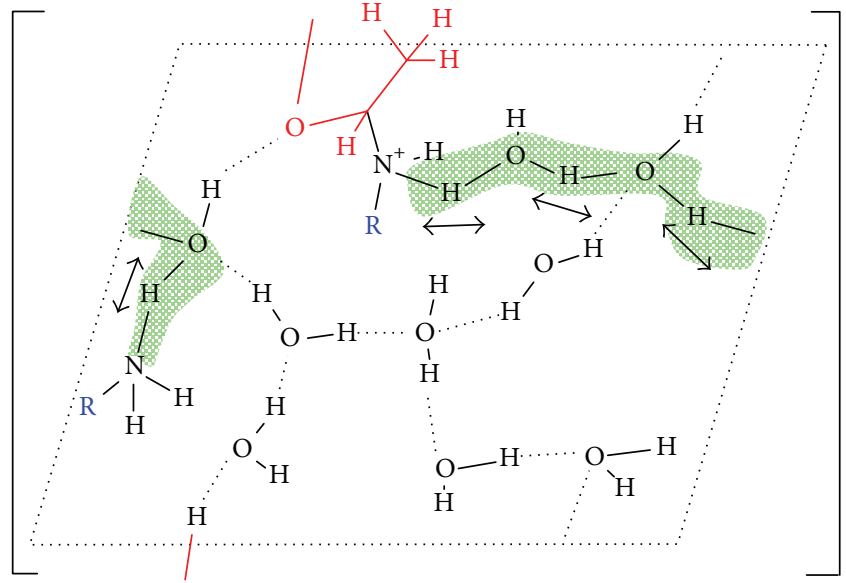

Scheme 2: Transition state of reaction between PE (blue color) and acetaldehyde (red colour), showing the boundary translation invariance property of PE-surface periodic model. Arrows and green shadows indicate the direction and the protons involved in the transfer, dotted lines represent hydrogen bonds, and R corresponds to $\mathrm{PE}$ molecules which contain the amine groups.

accessible simulation times, being not possible, match the kinetics of the studied process by the time span simulated.

An additional limitation in membrane models is the size of the models; it is limited to several nanometres. Thus, no phenomena happening at longer length scales can be studied, which includes, for instance, the creation of large water defects and pores [44]. Initial models of biological membranes were simple hydrated PC bilayers systems; the complexity of these models was gradually increased by successive addition to the bilayer of other natural membrane components like other phospholipids, cholesterol, peptides, and proteins (Figure 2) [43]. The necessity for probing larger simulations time and length scales of systems has been tried to be solved using coarse grained models of molecular systems as phospholipid bilayers [26, 46, 47]. These models represent the molecular systems by a reduced number of degrees of freedom, clustering groups of atoms into coarse grained sites, or beads, which lack atomic details but keep the critical features of the molecules which determine the physics 


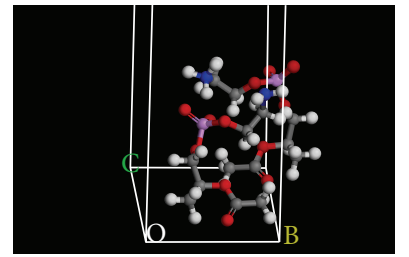

(a)

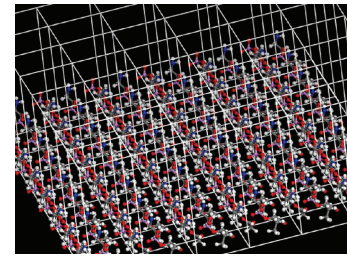

(b)

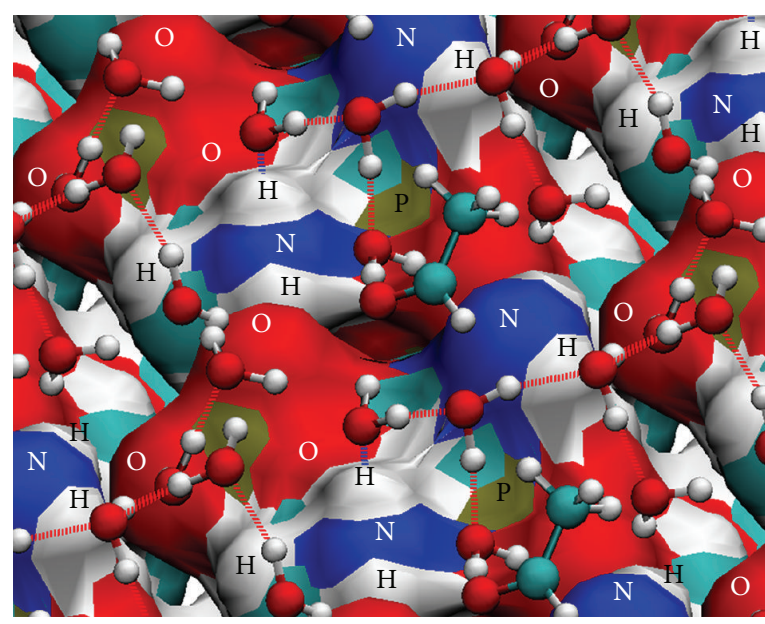

(c)

FIGURE 1: Model of phosphatidylethanolamine surface for study of Schiff base formation from PE and acetaldehyde. (a) Representation of cell unit of two molecules of truncated PE. (b) Extension of the cell by periodic boundary conditions. (c) A sight of PE surface, with acetaldehyde molecules and the water hydrogen-bond network. Atoms belonging to PE surface are labelled, and dotted lines represent hydrogen bonds.

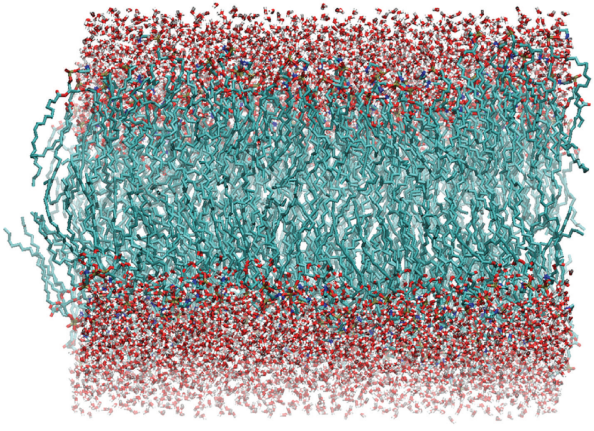

(a)

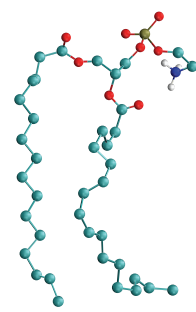

(b)

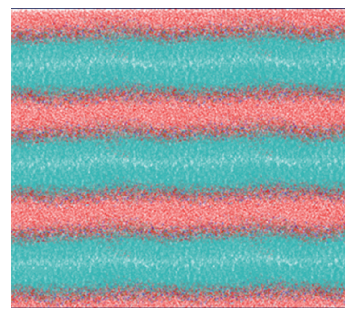

(c)

FIGURE 2: A simple model of 1-palmitoyl-2-oleoyl-phosphatidylethanolamine (POPE) bilayer. (a) Large POPE bilayer with 340 phospholipids and water molecules on its surfaces. (b) Backbone of POPE molecule. (c) Periodic boundary conditions in three dimensions of POPE bilayer model.

of the length scale under study $[46,48]$. In relation to studies of reactivity, all these methods at classical molecular mechanics level of calculus cannot be used for studying this kind of processes. However, in the case of membrane models, the results of simulations could lead to analyzing changes in the molecular interactions and biophysical properties of bilayers systems, by the introduction of some products of reactions into them that occurs on phospholipids (Table 2) [25-31].

This review is organized as follows. A description of the phospholipids reactivity as part of biological membranes is summarized first. The activity of reactive oxygen species (ROS) on phospholipid membranes, how ROS access them, and the oxidation reactions which yield reactive carbonyl species (RCS) are reviewed next. A brief description of generation of advanced lipoxidation end products (ALEs) and advanced glycation end products (AGEs) and their consequences on biophysical properties of membranes are also reviewed. Some general ideas and hypotheses about the biophysical impact of the modification of phospholipid membranes and the reactivity of different functional groups of phospholipids derived from theoretical studies are presented in all the items of this review.

\section{Phospholipid Reactivity}

The first comprehensive model of the biological membranes, the "fluid mosaic model," assumes the lipid bilayer to be a passive structure fulfilling two basic functions: supporting proteins and forming a barrier for dissolved molecules in the aqueous phase [49]. However, experimental data obtained in studies on biological and model membrane systems made lipid bilayer be also recognized as a potent enhancer and regulator of surface associated reactions [50-52]. In order to study lipid bilayer's structural complexity, Tieleman et al. proposed to divide the membrane into four different regions [43]. The second region is an interface which begins where water density is equal to that of headgroups and reaches the level of carbonyl groups. The interface also includes bounded ions and organized water molecules not easily to be described 
TABLE 2: Some articles related to studies of oxidation of phospholipids which use molecular dynamics simulations.

\begin{tabular}{|c|c|c|c|}
\hline Phospholipid molecular systems & $\begin{array}{l}\text { Simulation time } \\
\text { lipid force field }\end{array}$ & Aim & Reference \\
\hline $\begin{array}{l}30 \text { molecules of } \mathrm{O}_{2}^{-}, \mathrm{HO}_{2}, \mathrm{H}_{2} \mathrm{O}_{2}, \mathrm{HO} \text {, or } \mathrm{O}_{2} \text { placed } \\
\text { together at the aqueous phase surrounding a bilayer } \\
\text { containing } 128 \\
\text { 2-oleoyl-1-palmitoyl-sn-glycero-3-phosphocholine } \\
\text { (POPC) molecules. }\end{array}$ & $\begin{array}{l}50 \mathrm{~ns} \\
\text { Gromos 53A6 }\end{array}$ & $\begin{array}{l}\text { Studying the distribution, } \\
\text { mobility, and permeation of ROS } \\
\text { at phospholipid bilayers. }\end{array}$ & {$[25]$} \\
\hline $\begin{array}{l}\text { Coarse grained bilayer models containing different } \\
\text { proportions of } \\
\text { 1,2-dilinoleoyl-sn-glycero-3-phosphocholine (DUPC), } \\
\text { cholesterol, and } \\
\text { 1-palmitoyl-2-azelaoyl-sn-glycero-3-phosphocholine as } \\
\text { oxidized lipid specie. }\end{array}$ & $\begin{array}{l}4-20 \mu \mathrm{s} \\
\text { Martini coarse } \\
\text { grained }\end{array}$ & $\begin{array}{l}\text { Evaluate a protector role of } \\
\text { cholesterol on phospholipid } \\
\text { bilayers from disruption caused } \\
\text { by lipid oxidation. }\end{array}$ & {$[26]$} \\
\hline $\begin{array}{l}\text { Bilayers, each one containing cholesterol and } 128 \\
\text { phospholipids with varying POPC to } \\
\text { 1-palmitoyl-2-glutaryl-sn-glycero-3-phosphocholine } \\
\text { (PGPC); the last is an oxidized lipid, with a truncated } \\
\text { carbon chain terminated with a carboxylic acid. }\end{array}$ & $\begin{array}{l}100 \mathrm{~ns} \\
\text { Berger's } \\
\text { nonpolarizable } \\
\text { united-atom }\end{array}$ & $\begin{array}{l}\text { Evaluate overall changes of the } \\
\text { membrane structural and } \\
\text { dynamical properties once they } \\
\text { become oxidized. }\end{array}$ & {$[27]$} \\
\hline $\begin{array}{l}2 \text { molecules of 16-doxyl stearic acid randomly placed in } \\
\text { each leaflet of a bilayer containing } 62 \text { phospholipid } \\
\text { molecules each of 1-palmitoyl-2-(13-hydroperoxy-9,11- } \\
\text { octadecanedienoyl)-lecithin and } \\
\text { 1-palmitoyl-2-linoleoyl-glycero-3-phosphocholine } \\
\text { (PLPC). }\end{array}$ & $\begin{array}{l}200 \mathrm{~ns} \\
\text { modified Berger }\end{array}$ & $\begin{array}{l}\text { Studying lipid peroxidation } \\
\text { effects on bilayers properties. }\end{array}$ & {$[28]$} \\
\hline $\begin{array}{l}\text { Bilayers containing } 128 \text { molecules of POPC and } \\
\text { oxidized phospholipids PoxnoPC and PazePC in } \\
\text { different proportions. PoxnoPC has a carbonyl group, } \\
\text { and PazePC has an anionic carboxyl group pendant at } \\
\text { the end of the short, oxidized acyl chain. }\end{array}$ & $\begin{array}{l}100 \mathrm{~ns} \\
\text { united-atom Berger }\end{array}$ & $\begin{array}{l}\text { Evaluate the perturbation of } \\
\text { overall membrane structural and } \\
\text { dynamic properties by } \\
\text { oxidatively modified } \\
\text { phospholipids. }\end{array}$ & [29] \\
\hline $\begin{array}{l}\text { Bilayers containing } 72 \text { molecules of PLPC and oxidized } \\
\text { PLPC (oxPLPC) molecules in different proportions. } \\
\text { OxPLPC contained modified linoleoyl residues: } \\
\text { 12-oxo-cis-9-dodecenoate and 13-hydroperoxy-trans-11, } \\
\text { cis-9-octadecadienoate. }\end{array}$ & $\begin{array}{l}25 \mathrm{~ns} \\
\text { OPLS }\end{array}$ & $\begin{array}{l}\text { Observing the effect of oxidized } \\
\text { lipids on the sensitivity of a } \\
\text { bilayer to electroporating fields. }\end{array}$ & {$[30]$} \\
\hline $\begin{array}{l}\text { PLPC bilayers containing } 72 \text { lipids, replacing } 2,4,8,18 \text {, } \\
\text { and } 36 \text { PLPC lipid molecules with each oxidized lipid. } \\
\text { The oxidized lipid was modeled by addition of a } \\
\text { hydroperoxide group at position C } 9 \text { or C13 of the } \\
\text { linoleate tail and shifting the double bonds. }\end{array}$ & $\begin{array}{l}180 \mathrm{~ns} \\
\text { united-atom }\end{array}$ & $\begin{array}{l}\text { Studying the effect of lipid } \\
\text { peroxidation on the properties of } \\
\text { PLPC bilayers. }\end{array}$ & {$[31]$} \\
\hline
\end{tabular}

with macroscopic theories. This apparent simple interface of one componential lipid bilayer is actually a region with complex structure, sensible to changes in its physicochemical properties as a result of changes in its composition. For example, when water concentration decreases, dielectric permittivity changes from nearly 80 to about 2 (over a distance of about $1 \mathrm{~nm}$ [53]), and dipole potential affects electrostatic potential at the immediate vicinity of the membrane or within the interface [50].

The membrane surfaces are so complex, having developed some electrostatic models for describing their properties. One of them is Gouy-Chapman electrostatic theory which relates the charge density and electrical potential at the surface of a membrane to the concentrations of ions in the external solution, treating the interface as a charged structureless plain surrounded by uniform environments $[50,54]$. Actually, the membrane charges are not smearedout uniformly over the surface and the transition between the bulk solvent and the membrane interior is not discontinuous. The membrane charges are always discrete and distributed throughout a mesh-like, water-containing region. Their arrangement depends on the type of lipid present in the membrane. The variety of lipids and their biological functions suggest that charge distribution determines the extent and type of interaction with surface associated molecules [50]. The solvent properties and ion concentration in this region may differ largely from the bulk, and they also could be modified taking into account possible appendages in the surface, which range from glycolipid and protein molecules, with dimensions on the order of a few nanometers, to cilia and microvilli, on the order of micrometers [54].

The amount of water and its organization and mobility change with its distance from the aqueous phase to the surfaces [43, 55-57]. Particularly, the organization of water around charged surfaces greatly affects effective electrostatic potential. Zwitterionic headgroups of phospholipids create 
dipole and higher multipole fields which, in principle, could be relevant for the membrane hydration $[54,58]$. Theoretical studies have shown that water molecules close to a polar surface are oriented by an electrostatic field associated with lipid residual charges [59, 60]. Moreover, water-membrane association has been inferred to be governed by chargetransfer rather than by charge-charge interactions, being one source of such effects, the strong local interactions such as atomic or dipolar-fields near the individual charged or polar groups at the membrane surface [54]. These interactions are also involved in the hydrogen bonds or other charge-transfer processes between the water molecules and the membrane constituents and/or between themselves.

The particular chemical environment of this interface makes phospholipids surface interact with not only small molecules [61-64] but also macromolecules [65-67], via electrostatic and hydrophobic interactions and/or hydrogen bonding. The cell membrane surface could also enhance the ability of protons to diffuse promptly along the membrane through hydrogen-bonded networks of water molecules and charged or polar groups of phospholipids at the surface [68]. The membrane-buried layers of these networks can eventually serve as a storage/buffer for protons (proton sponges) $[69,70]$. Phospholipid components of cell membrane also exhibit particular reactivity in this interface, which has been evidenced experimentally [21, 71-76] and theoretically [19, $20,22,23,77]$. Several of these experimental and theoretical studies suggest the catalytic potential of phospholipids surface for participating in other reactions that occurs on cell membrane surface. Beyond surface charge, the phospholipid headgroups may also affect other physicochemical properties of phospholipid bilayers, such as packing of the lipid chains, the thermotropic phase behavior, and the isothermal lateral phase separation of the bilayer into discrete domains of different compositions [78].

Phosphatidylethanolamine (PE) is recognized as one of the main components of biological membranes, being one of the most abundant lipids in eukaryotic cell membranes unevenly distributed between the inner and the outer leaflets of the bilayer [79]. Its presence under possible primitive earth conditions was also hypothesized [80] and also performs many biological roles beyond its structural role, having, for example, a contribution to apoptosis and cell signaling [8183 ], as donor of the ethanolamine moiety that covalently modifies several proteins $[84,85]$. Our theoretical studies about several reactions on PE surface (Table 1) attributed an additional role to $\mathrm{PE}$, a catalytic role through its amine and phosphate groups in the context of a model which simulate the interface water/PE-monolayer $[19,20,22,23$, 77]. This PE-surface model is a three-dimensionally periodic slab model. In all the studied reactions, the supercells contained two molecules of truncated $\mathrm{PE}$, additional reactive molecules, and sufficient number of water molecules as explicit solvent in a hydrogen-bond network along the polar heads of phospholipids. The periodic boundary conditions made it possible to obtain a surface model of a layer of phospholipids, useful for studying theoretically the reactions on an environment different to aqueous solvent (Figure 1). The catalytic effect of PE surface was interpreted in three ways: (i) accumulation of water molecules on the surface, increasing their organization, reducing their mobility, and polarizing their bonds as a result of an interaction with the PE charged groups; (ii) direct acid catalysis through amine groups of $\mathrm{PE}$ molecules adjacent to reactive $\mathrm{PE}$ molecule acting as donors or acceptors in the proton transfers, and water molecules in the surface surroundings acting as bridges in the proton exchange between donor and acceptor protons in the reaction (Scheme 2 and Figure 3); (iii) passive catalytic effect through a charge stabilization of different intermediate structures of reaction, due to direct electrostatic interactions with the charged groups generated in the different steps of the reaction. In this particular chemical environment, the role of water molecules in the direct proximity of PE surface was not only as solvent, if not, it is also catalytic, acting as bridge between proton donor and acceptor groups and stabilizing electrostatically transition states and intermediates structures through hydrogen bonds with charged and polar groups of them. These results were in agreement with experimental data about these reactions $[21,86]$ and concluding in the catalytic potential of phospholipids surfaces for participating in other reactions that occur on the cell membrane surface.

It is known that considering surface as a chemical environment for biochemical reactions brings changes in their characteristics [50]. Membrane-associated reactions are controlled by the transmembrane and lateral distribution of reactive molecules, which depends ultimately on the state of the lipid bilayer and the efficiency of its transport mechanisms. On the other hand, biochemical reactions occurring in aqueous solutions are controlled almost exclusively by diffusion [50]. In the studied reactions on PE surface, the catalytic effect of the surface was evidenced through the reduction of free energy barriers in the reaction pathways in comparison with the same reactions studied in pure water models, such as Schiff base formation, Amadori rearrangement, and hydrogen peroxide decomposition [19, 20, 22, 77].

Although phosphatidylserine (PS) represents a quantitatively minor phospholipid in mammalian cells, the presence of PS is also required for many fundamental cellular processes. Its distribution is asymmetrical in the plasma membrane, constituting $\sim 25 \%$ of the phospholipid in the inner leaflet, what carries an appreciable negative charge above the cytosolic surface of the plasma membrane, in comparison with other intracellular membranes, creating a chemical environment where special biochemical process occurs $[87,88]$. It is known that changes in the PS distribution have strong consequences when PS molecules naturally flip to the outer surface; they act as a signal for macrophages to phagocyte the cells $[89,90]$. By itself, PS keeps several described reactivity properties described for PE, participating in analogous reactions [91, 92]. However, PS participates in many intracellular processes depending on its anionic nature. For example, some key signaling proteins, such as the tyrosine kinase and Src as well as the Ras and Rho family of GTPases, contain positively charged motifs that bind to PS [93-96]. Electrostatic attraction between anionic groups of $\mathrm{PE}$ and positively charged regions on proteins has been suggested to contribute as a driving force for the plasma membrane localization of these peripheral proteins [87]. 


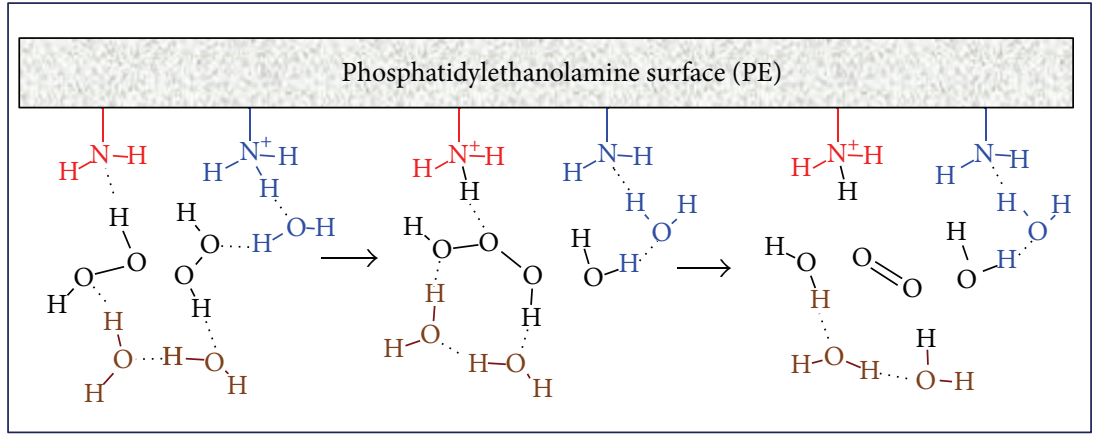

(a)

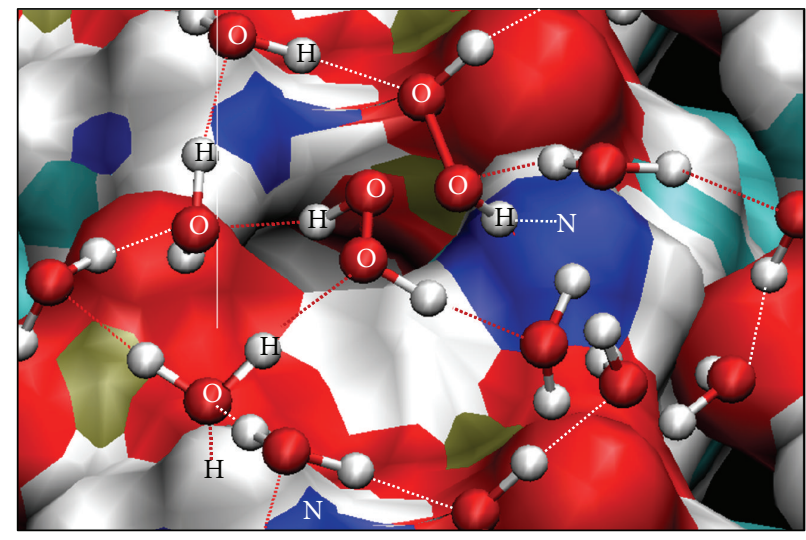

(b)

Figure 3: Pathway for hydrogen peroxide decomposition on PE surface. (a) Scheme of two steps of reaction, formation of an intermediate hydrogen trioxide from two $\mathrm{H}_{2} \mathrm{O}_{2}$ molecules and its hydrolysis in $\mathrm{O}_{2}$ and $\mathrm{H}_{2} \mathrm{O}$. (b) Starting structure of modelled reaction, including two molecules of hydrogen peroxide, a PE surface, and solvent molecules, forming a hydrogen-bond network. Atoms which participate in the reaction are labelled; dotted lines represent hydrogen bonds.

Phosphatidylcholine (PC) is the major phospholipid in mammalian membrane and is synthesized in the liver via the choline pathway by methylation of $\mathrm{PE}$ via phosphatidylethanolamine $\mathrm{N}$-methyltransferase [97]. In addition to its function as a membrane constituent, $\mathrm{PC}$ has a role in signalling via the generation of diacylglycerols by phospholipase C, being also precursor for phosphatidic acid, lysophosphatidylcholine, and platelet-activating factor, each with important signalling functions, and other structural lipids such as sphingomyelin and PS. PC in its form of dipalmitoylphosphatidylcholine (DPPC) has been considered the benchmark lipid in the study of model bilayers, experimentally and theoretically [43]. The hydration of the headgroups is probably the most drastic difference between PC and PE as component of cell membranes; around the PC headgroup, the water molecules orient themselves in a clathrate structure, characteristic of solvation shells of hydrophobic solutes. On the other hand, the PE headgroup solvation involves hydrogen bonding with water molecules and other PE headgroups $[98,99]$. This difference is attributed to the larger hydrogen-bonding possibilities of the PE headgroups with easily available polar hydrogens, in comparison with the PC headgroup with bulky methyl groups instead [43]. The same structural features make PC not exhibit the same reactivity of PE. However, a catalytic effect of PC on hydrogen peroxide decomposition has been suggested based on experimental results using PC vesicles [21].

Knowing the catalytic potential of phospholipids surface could be also important in the emerging field of synthetic biology [100], for constructing novel biological systems, which function in a robust and predictable manner in novel biological contexts, useful as biotechnological tools, biomedical devices, or biofunctional materials [101]. It has been shown that some PE-based liposomes of various compositions are stable and $\mathrm{pH}$-sensitive [102-104]. An acidification of the environment leads to membrane destabilization, fusion, and release of entrapped aqueous vesicle contents, being for that useful for the delivery of foreign substances as drugs into living cells. They have been tested as an efficient drug delivery system in the treatment of malignant tumours [105]. PE conjugated with hydrophilic polymers as polyethylene glycol forms polymeric micelles which have also been useful as drug delivery systems [106-108]. 


\section{Reactive Oxygen Species and Phospholipid Membranes}

Reactive oxygen species (ROS) are generated from the metabolism of molecular oxygen and participate in redox signaling pathways that are essential for the physiological control of cell function $[109,110]$. However, they are also involved in the process of aging and several chronic diseases such as atherosclerosis, diabetes, Alzheimer's disease, asthma, rheumatoid arthritis, and many forms of cancer, being also generated by numerous extracellular agents such as pollutants, tobacco smoke, iron salts, and radiation [110, 111]. ROS include free radicals such as superoxide radical $\left(\mathrm{O}_{2}{ }^{-}\right)$, nitric oxide radical $\left(\mathrm{NO}^{\circ}\right)$, hydroxyl radical $\left(\mathrm{OH}^{\bullet}\right)$, and hydroperoxyl $\operatorname{radical}\left(\mathrm{HOO}^{\circ}\right)$ as well as nonradical molecules like hydrogen peroxide $\left(\mathrm{H}_{2} \mathrm{O}_{2}\right)$, ozone $\left(\mathrm{O}_{3}\right)$, trioxidane $(\mathrm{HOOOH})$, and nitric oxide (NO) $[109,110]$. Radical species such as $\mathrm{OH}^{\bullet}$ and, to a lesser degree, $\mathrm{O}_{2}{ }^{-}$tend to be regarded as more reactive and poorly selective, whereas many nonradical species such as $\mathrm{H}_{2} \mathrm{O}_{2}$ show more selectivity in their reactions with biomolecules being able to migrate in aqueous medium freely [112].

The vulnerability of membrane phospholipids to be damaged by ROS is related to the physicochemical properties of the membrane bilayer and the chemical reactivity of the fatty acyl chains composing the membrane [113]. The first property is related to the fact that oxygen and free radicals exhibit more solubility in the fluid lipid bilayer than in the aqueous solution. The values of solubility of $\mathrm{O}_{2}$ are approximately 20-30 more than aqueous media [114], making it readily available to fuel these reactions in a lipid environment, where it also increases its reactivity in comparison with the surrounding aqueous medium [115]. On the other hand, classical molecular dynamics simulations have shown that hydroxyl and hydroperoxyl radicals were able to penetrate deep into the lipid headgroups region, having access to potential peroxidation sites along the lipid hydrocarbon chains, without having to overcome the permeation free energy barrier [25]. In this point, it is necessary to take into account the case of short-lived radicals such as $\mathrm{OH}^{\circ}$, where its steady-state is a result of competing processes of radical generation and scavenging rather than an equilibrium distribution over larger distances. The hydroxyl radical $\left(\mathrm{OH}^{*}\right)$ diffuses in aqueous solution via $\mathrm{H}$-transfer reactions with solvent molecules which has been shown by Car-Parrinello molecular dynamics [116]. The solubility of other ROS such as superoxide $\left(\mathrm{O}_{2}{ }^{-}\right)$radical and hydrogen peroxide $\left(\mathrm{H}_{2} \mathrm{O}_{2}\right)$ is less in the fluid lipid bilayer, remaining at the aqueous phase.

Once ROS are inside biological membranes, in particular, free radicals ROS are able to induce peroxidation of membrane lipids, above all in membranes composed of residues of phospholipids with polyunsaturated fatty acids (PUFAs) [117]. PUFAs are generated by action of desaturases on saturated fatty acids, being essential components of cellular membranes in higher eukaryotes, but, at the same time, they are extremely sensitive to oxidation [113]. Then, in comparison with other peroxidation processes, PUFA peroxidation has a self-propagating nature, because abstraction from a methylene group of a hydrogen atom has as a result an unpaired electron on the carbon, $\left(-^{\bullet} \mathrm{CH}-\right)$. C-H bonds on the carbon atom nearby the PUFA double bond are weakened by its close presence, facilitating the hydrogen subtraction [117, 118]. In general, lipid peroxidation reaction has three steps: initiation, propagation, and termination (Scheme 3). The initiation step between ${ }^{\circ} \mathrm{OH}$ radical and polyunsaturated fatty acyl chains generates a lipid radical $\left(\mathrm{L}^{\circ}\right)$, which in turn reacts with molecular oxygen to form a lipid peroxyl radical ( $\left.\mathrm{LOO}^{\circ}\right)$. Propagation step starts with a hydrogen abstraction by $\mathrm{LOO}^{\circ}$ from an adjacent fatty acyl chain, producing a relatively stable lipid hydroperoxide $(\mathrm{LOOH})$ and a second lipid radical [119]. Then, reduced metals, such as $\mathrm{Fe}^{2+}$, can cleave reductively $\mathrm{LOOH}$, producing lipid alkoxyl radical ( $\left.\mathrm{LO}^{\circ}\right)$. Both peroxyl (LOO $\left.{ }^{\circ}\right)$ and alkoxyl $\left(\mathrm{LO}^{\circ}\right)$ radicals are able to propagate lipid peroxidation by abstracting additional hydrogen atoms [120]. Termination step includes the fragmentation of $\mathrm{LOOH}$, in the presence or absence of reduced metals or ascorbate, into a large variety of reactive intermediates called reactive carbonyl species (RCS) with three to nine carbons in length (Schemes 3 and 4). RCS (Scheme 5) include very reactive $\alpha, \beta$-unsaturated aldehydes such as 4-hydroxy-trans-2-nonenal (4-HNE), 4hydroxyhexenal (4-HHE), and acrolein, dicarbonyls such as malondialdehyde (MDA) and glyoxal, and keto-aldehydes such as 4-oxo-trans-2-nonenal (ONE) and isoketals [113, 119, 121]. Oxidation of n-6 PUFAs leads to the formation of 4HNE, whereas oxidation of n-3 PUFAs generates 4-HHE [122]. Phospholipids can also be attacked by reactive nitrogen species (RNS) and chlorine species, further expanding the range of products to nitrated and chlorinated phospholipids [112].

Resulting oxidized phospholipids are able to modify the function and physical properties of the membranes, including their fluidity, permeability to different solutes, bilayer thickness, and the packing of lipids and proteins in the membranes [78]. Experimental and theoretical studies on model membranes with introduced oxidized lipids demonstrated that cell membrane damage by oxidative stress causes alteration of water penetration in the bilayer, due to an increase in polarity and hydrogen-bonding propensity in the central region of the bilayer [28]. The oxidized lipid tails have the tendency to bend toward the water interface, because they are more polar and can be shorter in length, due to the presence of aldehyde or hydroperoxide groups. This tendency is responsible of the changes in the structural properties of the lipid bilayers, increasing their water permeability, which lead to an increase in the average area per lipid and, correspondingly, to a decrease of the bilayer thickness $[28,29,31]$. These changes enhance the susceptibility of the membrane to electropermeabilization, a procedure which has as application the introduction of genetic material and pharmaceutical agents into living cells [30]. On the other hand, the accumulation of lipoperoxidation products as malondialdehyde is able to disturb the aminophospholipids organization in the human erythrocyte membrane bilayer, compromising its integrity [123]. The membranes composition could influence the degree of damage caused by phospholipid oxidation. A coarse grained molecular dynamics study attributes to cholesterol a protecting role on bilayers 


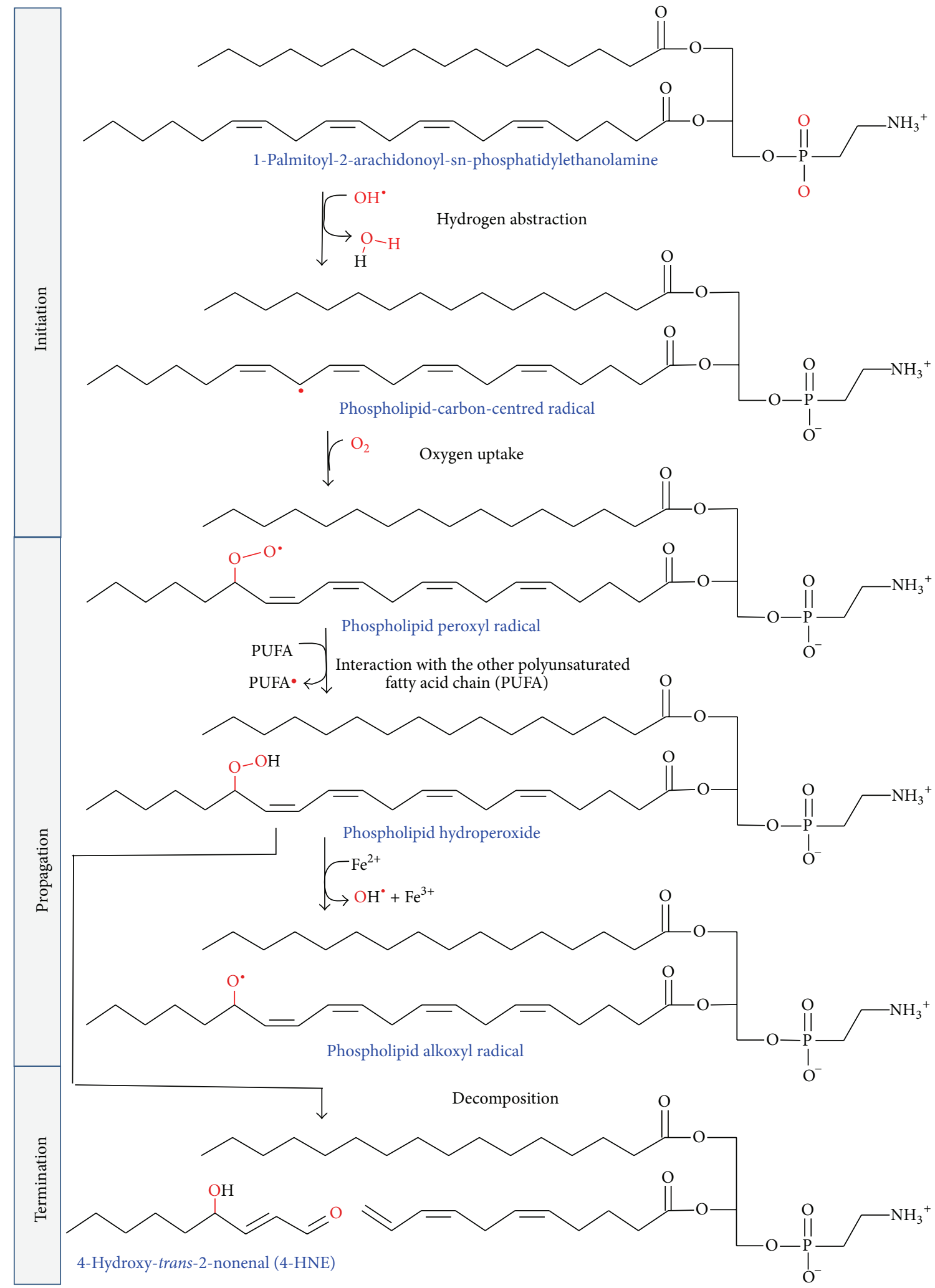

Scheme 3: Scheme of the steps in lipid peroxidation of 1-palmitoyl-2-arachidonoyl-sn-phosphatidylethanolamine. 


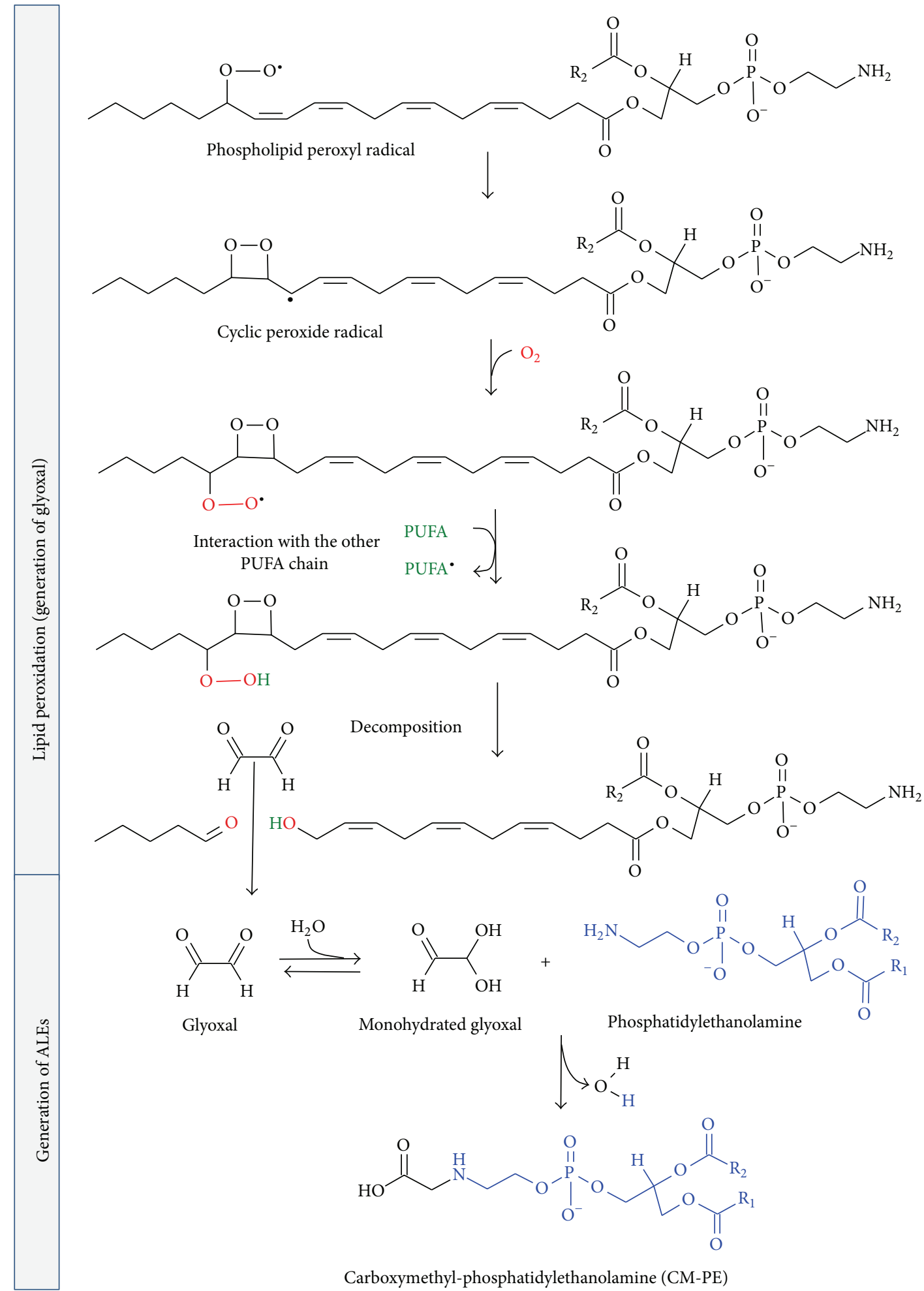

Scheme 4: Generation of ALEs from phospholipid peroxidation, showing possible routes to formation of glyoxal and subsequent CM-PE. $\mathrm{R}_{1}, \mathrm{R}_{2}$ correspond to fatty acyl chains of phospholipids. 


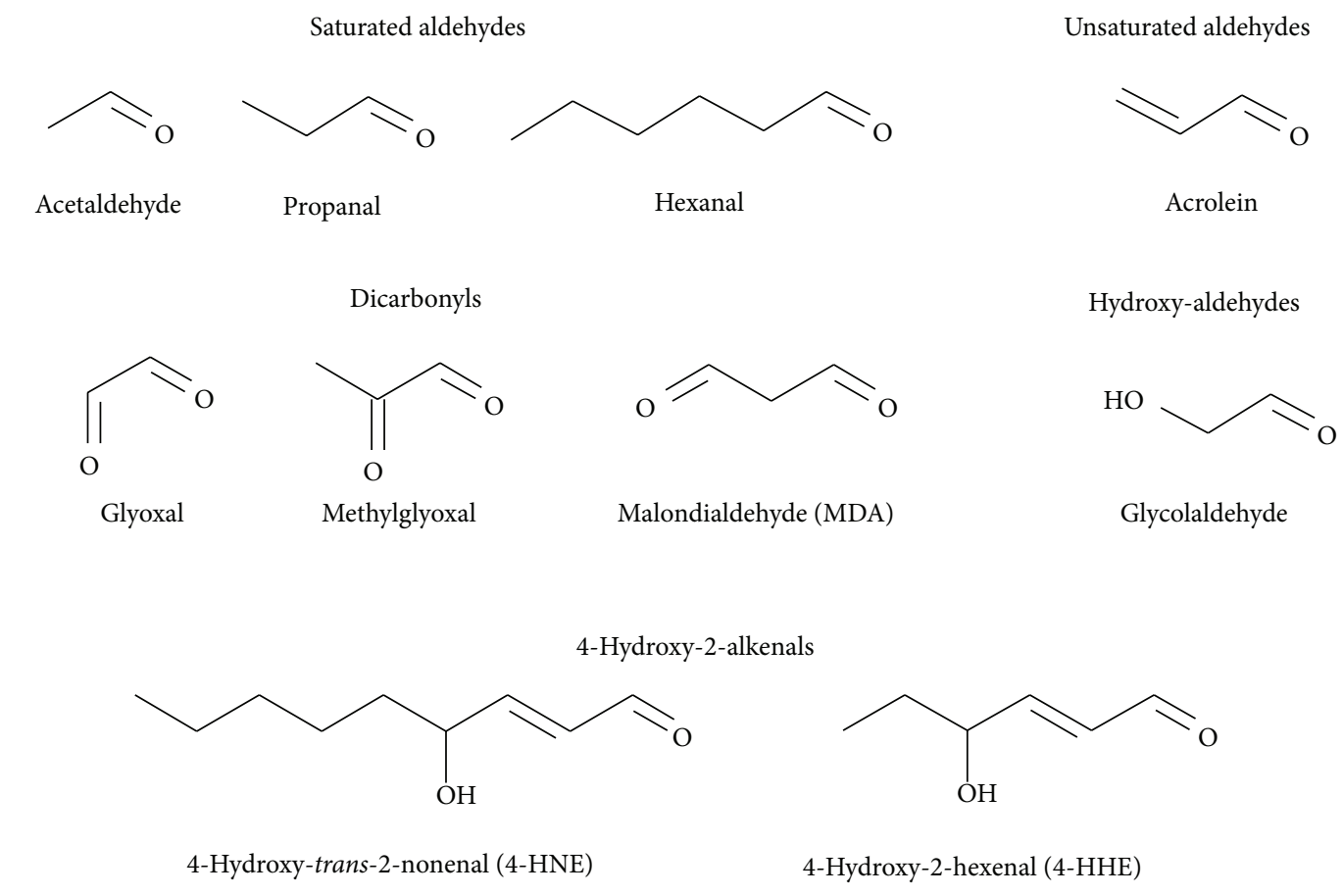

Polyhydroxy-dicarbonyls<smiles>O=CC(=O)C(O)C(O)CO</smiles>

Ribosome<smiles>O=CC(=O)C(O)C(O)C(O)CO</smiles>

Glucosone<smiles>O=CC(=O)CC(O)C(O)CO</smiles>

3-Deoxyglucosone

Other reactive carbonyl species<smiles>O=CC(O)CO[PbH2]</smiles>

Glyceraldehyde-3-phosphate<smiles>O=C(O)CO[PbH2]</smiles>

Dihydroxyacetone phosphate<smiles>CCCCCC(=O)/C=C/C=O</smiles><smiles>O=C1OC(C(O)CO)C(=O)C1=O</smiles>

Dehydroascorbate

4-Oxo-trans-2-nonenal

Scheme 5: Chemical formulae of most common biological reactive carbonyl species.

from disrupting agents as oxidized phospholipids [26]; this role is related to the cholesterol rearrangement in the oxidized membrane exhibiting a preferable interaction with carbonyls of the oxidized chains [29].

Generally, phospholipid headgroups are not affected by peroxidation reactions. However, these headgroups could influence the rates of peroxidation which has been shown in studies using phospholipid liposomes [78]. There is experimental and theoretical evidence that $\mathrm{H}_{2} \mathrm{O}_{2}$ decomposition is accelerated above phospholipids membranes surface [20, 21], having in this way an indirect protective effect against the possible damage caused by this nonradical ROS. Our 
group developed a mechanism of this reaction by two steps (Figure 3(a)). In the first step, an intermediate hydrogen trioxide from two $\mathrm{H}_{2} \mathrm{O}_{2}$ molecules is formed. In the second step, this intermediate is cleaved in $\mathrm{O}_{2}$ and $\mathrm{H}_{2} \mathrm{O}$ [20] (Figure 3(a)). The results have also shown the first step as the limiting step of the reaction, having a free energy barrier of $8.76 \mathrm{kcal} \mathrm{mol}^{-1}$ in comparison with the same reaction in a pure water model where this barrier had a value of $25.56 \mathrm{kcal} \mathrm{mol}^{-1}$. This catalytic effect of PE surface was done directly by amine groups of $\mathrm{PE}$ and water molecules in the proximity of $\mathrm{PE}$ surface being part of the hydrogen-bond network. The two PE molecules of the system acted like proton donor and acceptor, assisting directly the reaction in the deprotonation of the first $\mathrm{H}_{2} \mathrm{O}_{2}$ molecule (Figure 3). The role of components of $\mathrm{PE}$ surface was not only limited to participate in proton transfer, if not also favouring accumulation of the main reactive $\mathrm{H}_{2} \mathrm{O}_{2}$ on the proximity of the surface. The phosphate anion of phospholipids forms hydrogen bonds with water molecules in the network connecting donor and acceptor protons (Figure 3(b)); it could facilitate accumulation of $\mathrm{H}_{2} \mathrm{O}$ on the membrane surface and in consequence of $\mathrm{H}_{2} \mathrm{O}_{2}$ in its proximity, raising local concentrations of the last as a result. The $\mathrm{H}_{2} \mathrm{O}_{2}$ decomposition on phospholipids surfaces could contribute to other biochemical mechanisms such as natural antioxidant molecules as ascorbate $[124,125]$ and antioxidant enzymes $[126,127]$ for regulating the concentration of $\mathrm{H}_{2} \mathrm{O}_{2}$, being able to cause biological damage. It is also essential for functions related to signal transduction, cell growth enhancement, cell proliferation, cell differentiation, and apoptosis at moderate concentrations [128-132].

\section{Advanced Lipoxidation End Products (ALEs)}

The reactive carbonyl species (RCS), mainly short-chain aldehydes (Scheme 5) generated during lipid peroxidation, have longer half-life values in comparison with ROS or RNS, being able to migrate through hydrophobic and hydrophilic media due to their polar and noncharged structure. RCS are electrophilic and therefore highly reactive toward nucleophilic groups in biomolecules such as proteins, DNA, and aminophospholipids. Unsaturated RCS are usually an order of magnitude more reactive than their saturated counterparts $[133,134]$. These reactions result in the irreversible modification of biomolecules through the formation of a variety of adducts and cross-links collectively named advanced lipoxidation end products (ALEs).

Generation of ALEs involves the loss of function and structural integrity of modified biomolecules and may be the cause of subsequent cellular dysfunctions and tissue damage. In the proteins, their strong nucleophilic sites such as thiol, imidazole, and hydroxyl groups are the most attractive targets for electrophilic attacks of RCS. As an example, 4-HNE can react with histidine (His), cysteine (Cys), or lysine (Lys) residues of proteins, leading to the formation of stable Michael adducts with a hemiacetal structure [135]. The factors that can affect selectivity of oxidative damage to proteins could include their values of the half-life, their rate of proteolysis, their molecular conformations, presence of a metal-binding sites, and relative abundance of amino acid residues susceptible to oxidative reactions [113]. RCS can also react in the exocyclic amino groups of nucleotides to form various alkylated products, deoxyguanosine being the most commonly modified DNA base, because of its high nucleophilicity [136].

Aminophospholipids such as PE and PS can also react through their primary amino groups with RCS carbonyl compounds, obtaining analogous products from reactions between RCS and proteins. PE was found to be a good target for a reaction with 4-HNE, having as main product a Michael adduct which could be partly cyclized as a pyrrole derivative via a loss of water. On the other hand, PS reacted with 4-HNE poorly producing only a small amount of Michael adduct [137-139]. Isoketals have been also shown to react with $\mathrm{PE}$, forming pyrrole adducts and Schiff base adducts [140]. Excessive modification of plasma membrane aminophospholipids with the formation of ALEs modifies the composition of biological membranes, altering the asymmetrical phospholipid membrane distribution, resulting in changes in the membranes physical properties as fluidity which are translated in changes in membrane structure and function [136]. As examples, this membrane damage could alter the processes of biosynthesis and turnover of membrane phospholipids and the activity of membrane-bound proteins that require aminophospholipids for their function [136].

Some RCS such as glyoxal and methylglyoxal are generated also by sugar oxidative degradation pathways (Scheme 6), which include autoxidation reactions and Maillard reaction; thus, the corresponding reaction products with proteins or phospholipids can be named both as ALEs and AGEs or as EAGLEs (either advanced glycation or lipoxidation end products) [141]. Glyoxal could also be generated by myeloperoxidase-mediated degradation of serine at sites of inflammation and hydrolysis of ascorbate $[142,143]$. The amino group of aminophospholipids can also react with these carbonyl compounds and initiate some of the reactions occurring in proteins and DNA, leading to the formation of adducts such as carboxyethyl-PE and carboxymethyl-PE (CM-PE) (Scheme 4) $[144,145]$. The CM-PE generation in human erythrocytes and blood plasma has been demonstrated experimentally [145-147]. It is possible to hypothesize that the generation of CM-PE could proceed by similar mechanisms compared to CML (Scheme 6) [145, 148, 149]. Our group has obtained, using DFT calculations at DFT level of theory, a mechanism of formation of CM-PE from reaction between glyoxal and PE [23]. It has been hypothesized that carboxymethyl-PE could trigger pathological processes $[150,151]$, being suggested due its relationship with Maillard reaction, as a potentially sensitive marker for reflecting hyperglycemic conditions in the early stage of diabetes [145, 152].

The rates of oxidation and aldehyde adduct formation are low under physiological conditions [122]. However, they are increased during aging by a progressive decline in mitochondrial function which results in the accumulation of ROS [153, 154]. The rates of aldehyde adduct formation and glycation are also different between the different biomolecules with free amine groups, these rates being influenced by the half-life of them. In the case of proteins, there is a rapid turnover 


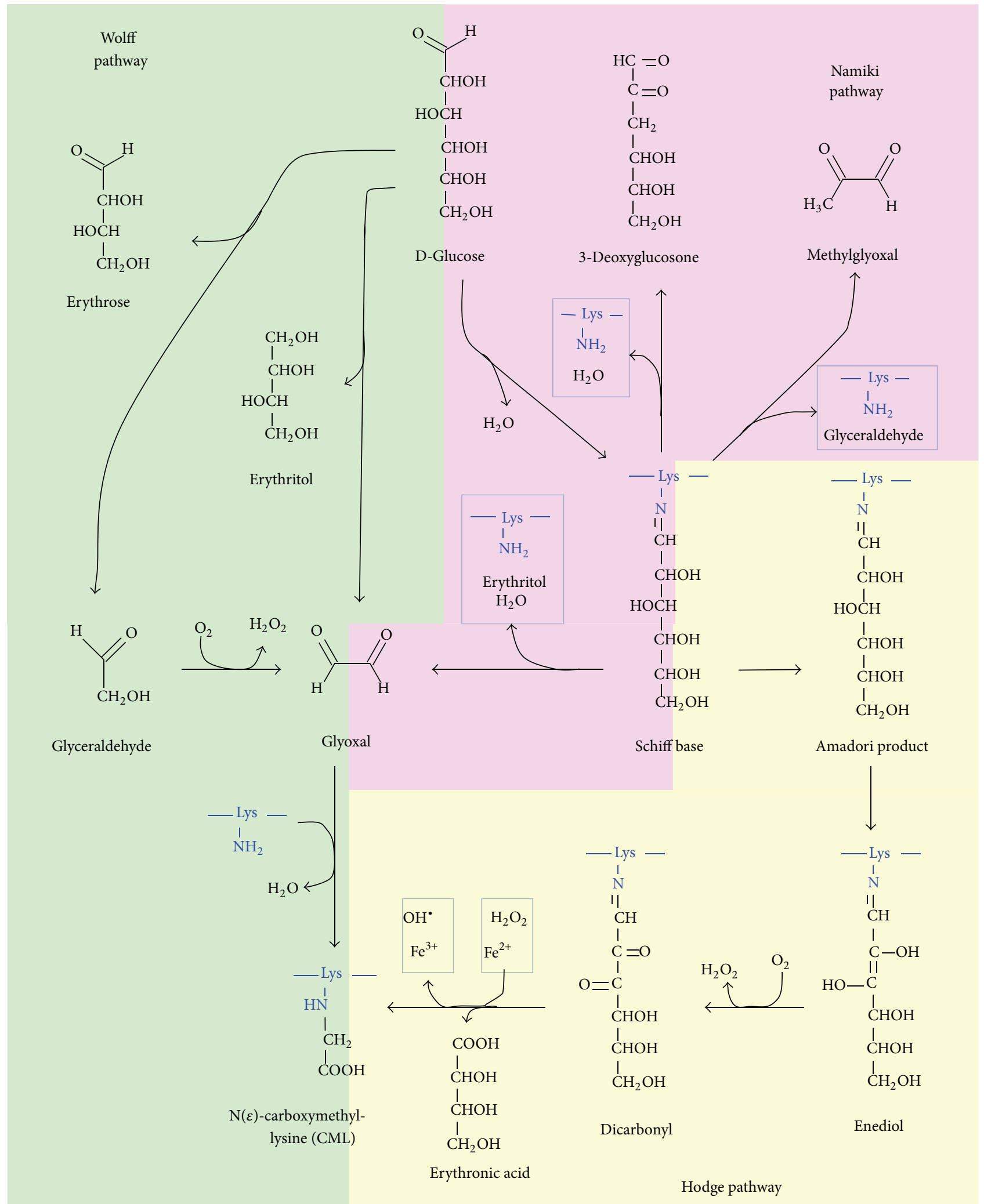

Scheme 6: Pathways leading to AGEs formation in proteins. They include Wolff, Namiki, and Hodge pathways, being also possible routes to formation of phospholipids AGEs. 
of short half-life of cellular proteins, there are proteolytic systems which ensure the removal of modified proteins, and proteasomal degradation is activated by oxidative stress, but their activities decline during the aging process, leading to the accumulation of damaged proteins and the formation of protein aggregates $[155,156]$. Moreover, there are a number of intracellular proteins such as elastin, eye lens crystallins, and several collagens, which evade the turnover process and instead are maintained on the order of years, being prone to accumulation of damage by oxidants and glycating agents $[157,158]$.

The half-life of phospholipids is consequence of a constitutive recycling of membrane phospholipids by a complex biochemical system, and it is more responsible to protect membranes from lipid oxidative damage than selective in situ repair [159]. The phospholipids half-life values depend on the cell type and cellular location; in the case of rat liver, an experimental research attributes values from 22 to 36 hours for the half-life of subcellular phospholipids [160]. According to experimental results, in rat brains the half-life of PE is 19.5 days taking into account the whole brain and 11.5 and 14.5 days considering only neurons and glial cells, respectively [161]. The diversity of turnovers for phospholipids increases if we take into account only molecular parts of them such as their fatty acyl chains, not sensible to attack of RCS or reducing sugars but sensible to ROS. In the n-3 PUFA adequate rat brains, $[4,5-3 \mathrm{H}]$ docosahexaenoic acid (DHA) has half-lives equal to 33 days in total brain phospholipid, and this time is prolonged by 15 weeks of nutritional deprivation of n-3 PUFA [162]. On the other hand, half-life for arachidonic acid from brain phospholipids is not altered by deprived diet, suggesting a different mechanism in comparison with DHA [163].

\section{Advanced Glycation End Products (AGEs)}

Advanced glycation end products (AGEs) are a complex and heterogeneous group of compounds, resulting from various pathways. One of them is a process known as nonenzymatic glycation, which includes a series of slow reactions between the carbonyl groups of reducing sugars such as glucose, fructose, or pentose and the amino groups of several kinds of biomolecules to yield an unstable Schiff's base followed by generation of stable ketoamine known as Amadori product (Scheme 7). The formation of Schiff's bases depends on the amount of reducing sugars and free amino groups of the biomolecules as well as an alkaline $\mathrm{pH}$ value. In contrast, Amadori rearrangements proceed at an acidic $\mathrm{pH}$ value and have a slower reaction rate [164]. Lastly, under certain conditions as high concentrations of glucose, oxidative and nonoxidative processes result in rearrangements and fragmentations of Amadori products into the irreversible AGEs (Hodge pathway) $[165,166]$. Formation of AGEs could also proceed from cleavage of Schiff's base intermediates (Namiki pathway) [167] as well as the formation of carbonyl compounds after autoxidation of monosaccharides, such as glucose, ribose, fructose, and glyceraldehyde (Wolff pathway) $[164,168]$ (Scheme 6).

Our group has experimental and theoretical background about Schiff bases formation and Amadori rearrangement mechanisms in different molecular systems $[19,22,73,74$, 77, 169-172]. A mechanism for the formation of Schiff base from acetaldehyde and PE on a model of phospholipids surface based on DFT calculations takes place in two steps, a formation of a carbinolamine intermediate, followed by its dehydration to Schiff base, with the dehydration being the rate-determining step of the process (Table 1), consistent with available experimental evidence for similar reactions [77]. The mechanism of the formation of the Amadori product from Schiff bases resulting from reactions between D-erythrose and PE has been studied [22]. The mechanism started with the formation of a 1,2-enaminol intermediate, followed by its ketonization to Amadori product (Scheme 7). The most important outcome of these studies was highlighting the catalytic role of PE surfaces on the reactions which proceed above them. It has been described in the item about aminophospholipids surface reactivity of this review. Moreover, the obtained mechanisms could be extrapolated to the reaction having glucose or other reducing sugars instead of D-erythrose, contributing towards better understanding a part of nonenzymatic glycation on phospholipid surfaces. In both mechanisms, all the reactions were governed to a great extent by the network of hydrogen bonds formed between water molecules on PE surface and the polar and charged groups of PE and acetaldehyde or Derythrose (similar to that obtained in Figure 1). Direct interactions between sugars and the lipid headgroups through the formation of hydrogen bonds have been demonstrated experimentally and through molecular dynamics simulations [34, 173-176].

Nonenzymatic glycation of proteins known as Maillard reaction is increased in diabetes mellitus patients and leads to several complications such as blindness, heart disease, nerve damage, and kidney failure [177]. One of the major AGEs of proteins widely found in vivo is the $\mathrm{N} \varepsilon$-(carboxymethyl) lysine (CML), which can be formed by three concurrent mechanisms in vivo [178]. The relationship with some diseases has been documented extensively $[106,179,180]$. In the classical Hodge pathway, Amadori product is oxidatively fragmented to give CML, among other products [181, 182]. In the "autoxidative glycosylation" pathway, CML is formed by the reaction between lysine and glyoxal, the latter of which results from metal-catalysed autoxidation of glucose by Wolff pathway $[168,183,184]$. In the third mechanism, glyoxal which can subsequently form CML is formed from fragmentation and oxidation of Schiff base via Namiki pathway $[167,185]$ (Scheme 6).

The nonenzymatic modification of amino groups in aminophospholipids also produces carboxymethyl compounds (Scheme 7), as CM-PE, whose generation in human erythrocytes and blood plasma has been demonstrated experimentally [145-147]. It is possible to hypothesize that the generation of CM-PE could proceed by similar mechanisms compared to CML, having as intermediate a dicarbonyl compound bound to $\mathrm{PE}$, as it was proposed for $\mathrm{N}^{\varepsilon}$-(carboxymethyl)lysine formation by a hydroxyl radical mediate pathway (Scheme 6) $[145,148,149]$. Similar to its Amadori-PE precursor, AGE-PE is also hypothesized to trigger pathological processes $[150,151]$, being suggested useful 


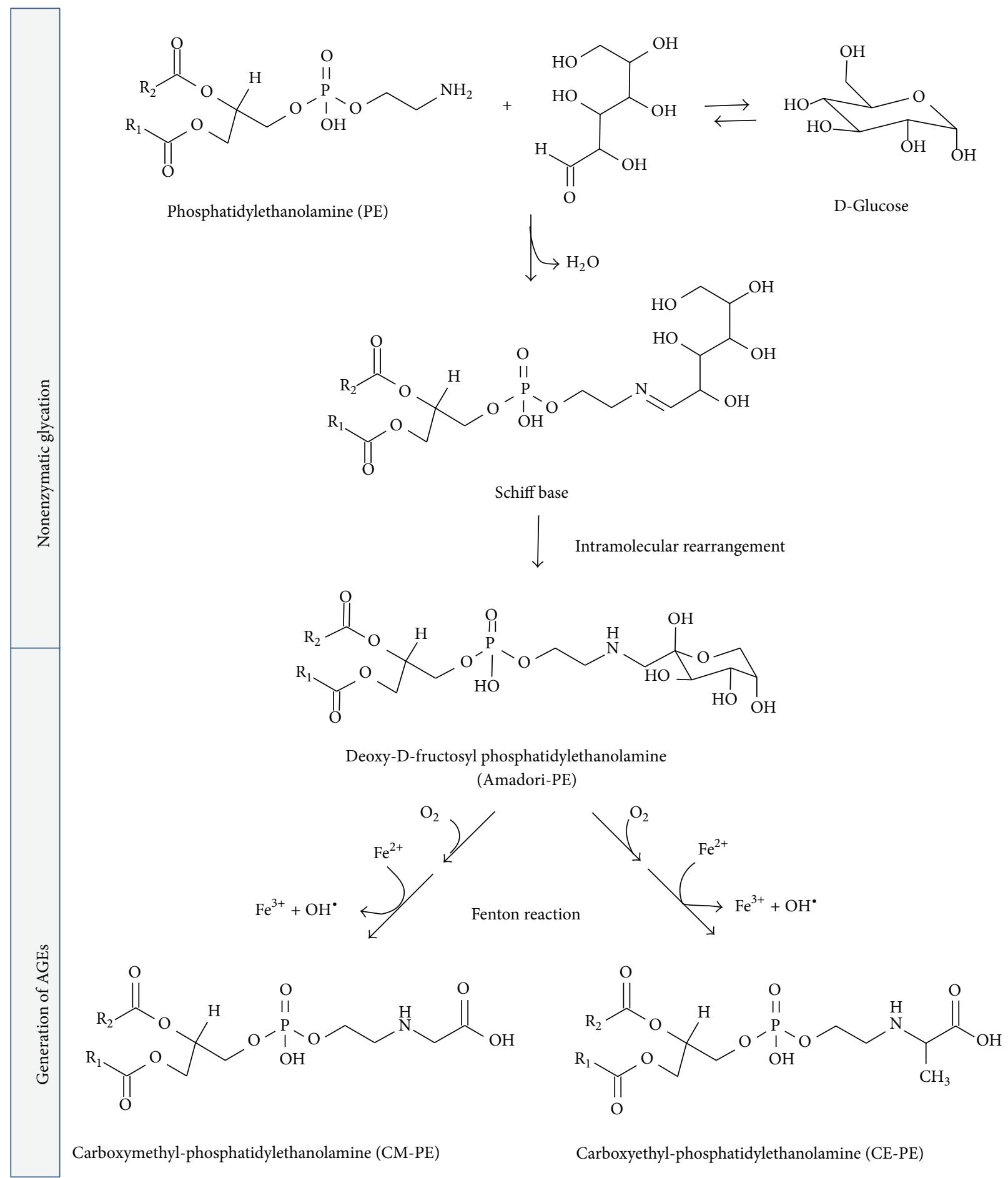

Scheme 7: Generation of AGEs from glycation of PE, showing possible routes to formation of CM-PE and CE-PE. $\mathrm{R}_{1}, \mathrm{R}_{2}$ correspond to fatty acyl chains of phospholipids.

as a potentially sensitive marker for reflecting hyperglycemic conditions in the early stage of diabetes $[145,152]$.

\section{Conclusions}

We reviewed some aspects related to nonenzymatic reactivity of membrane phospholipids, focusing on their roles as targets of reactions mediated by ROS or electrophilic compounds, such as RCS or reducing sugars, and their catalytic roles in some reactions that occurs on membrane surfaces. The formation of ALEs and AGEs has several intermediates and products characterized by their instability and differences in physicochemical properties. An example is glyoxal, a dicarbonyl intermediate which is generated by several pathways 
but rapidly generates other products, making their accurate quantification difficult in vivo [142]. In this context, theoretical methods which provide an atomistic-level description of these molecular systems are essential tools.

We described briefly some theoretical studies in order to gain insights about these processes at atomic level. These studies included calculus at DFT level of theory for obtaining mechanisms of reactions related to the formation of ALEs and AGEs using models of PE surface. Based on the results of these studies, it is possible to hypothesize that cell membrane phospholipids surface could enhance some reactions through a catalyst effect, and it could be a novel and accessory function of phospholipids surface into the cells. In their catalytic effect, the formation of hydrogen-bond networks between the phospholipids polar and charged groups and water molecules and a proton transfer is fundamental. These PE models were useful for obtaining insights about the reactivity on phospholipids surfaces, but if we desire to analyze the reactivity inside the membrane describing reactions as phospholipid peroxidation, the introduction of quantum mechanical/molecular mechanical (QM/MM) hybrid methods in these studies is desirable.

Other methods used for describing phospholipids bilayers were classical molecular dynamics simulations used in the study of formation of AGEs and ALEs for analysing the changes in the biophysical properties in the bilayer systems and the molecular interactions inside them generated by the introduction of some products of phospholipid peroxidation in the models or by their interaction with oxidant and reducing agents as ROS or sugars. In this point, the pathways of formation of ALEs and AGEs have common intermediates and products. The resulting ALEs and AGEs may be accumulated during aging and diabetes, introducing changes in cell membrane physicochemical and biological properties. Although the generation of RCS intermediates from lipids requires oxidative chemistry whereas nonenzymatic glycation may be either nonoxidative or oxidative, both pathways produce a number of carbonyl derivatives, which are responsible for the final production of ALEs and AGEs. Thus, although there are significant differences between the formation of ALEs and AGEs, many aspects of both pathways can be better understood if they are included in only one general carbonyl pathway that can be initiated by both lipids and carbohydrates [186]. More studies are desirable which could correlate the biophysics of modified phospholipids with metabolic studies in order to define the significance of the phospholipids properties for aging and the physiopathology of diseases such as diabetes, atherosclerosis, and Alzheimer.

\section{Conflict of Interests}

The authors declare that there is no conflict of interests regarding the publication of this paper.

\section{Acknowledgments}

The authors are grateful to the financial support of Govern de les Illes Balears (Grants nos. AAEE27/2014 and
AAEE044/2012). The authors are grateful to Centro de Cálculo de Computación de Galicia (CESGA) and the Centro de Cálculo de Computación de Cataluña (CESCA) for the access to their computational facilities. One of the authors (Christian Solís-Calero) wishes to acknowledge a MAE-AECI fellowship from the Spanish Ministry of Foreign Affairs and Cooperation.

\section{References}

[1] Y.-Y. Jiang, D.-X. Kong, T. Qin, X. Li, G. Caetano-Anollés, and H.-Y. Zhang, "The impact of oxygen on metabolic evolution: a chemoinformatic investigation," PLoS Computational Biology, vol. 8, no. 3, Article ID e1002426, 2012.

[2] A. J. García-Sáez and P. Schwille, "Surface analysis of membrane dynamics," Biochimica et Biophysica Acta-Biomembranes, vol. 1798, no. 4, pp. 766-776, 2010.

[3] E. Wallin and G. von Heijne, "Genome-wide analysis of integral membrane proteins from eubacterial, archaean, and eukaryotic organisms," Protein Science, vol. 7, no. 4, pp. 1029-1038, 1998.

[4] M. Pasenkiewicz-Gierula, K. Murzyn, T. Róg, and C. Czaplewski, "Molecular dynamics simulation studies of lipid bilayer systems," Acta Biochimica Polonica, vol. 47, no. 3, pp. 601-611, 2000.

[5] W. Dowhan, "The role of phospholipids in cell function," Advances in Lipobiology, vol. 2, pp. 79-107, 1997.

[6] C. R. Sanders and K. F. Mittendorf, "Tolerance to changes in membrane lipid composition as a selected trait of membrane proteins," Biochemistry, vol. 50, no. 37, pp. 7858-7867, 2011.

[7] A. Naudí, M. Jové, V. Ayala, R. Cabré, M. Portero-Otín, and R. Pamplona, "Non-enzymatic modification of aminophospholipids by carbonyl-amine reactions," International Journal of Molecular Sciences, vol. 14, no. 2, pp. 3285-3313, 2013.

[8] G. van Meer, D. R. Voelker, and G. W. Feigenson, "Membrane lipids: where they are and how they behave," Nature Reviews Molecular Cell Biology, vol. 9, no. 2, pp. 112-124, 2008.

[9] P. A. Janmey and P. K. J. Kinnunen, "Biophysical properties of lipids and dynamic membranes," Trends in Cell Biology, vol. 16, no. 10, pp. 538-546, 2006.

[10] G. J. Bartlett, N. Borkakoti, and J. M. Thornton, "Catalysing new reactions during evolution: economy of residues and mechanism," Journal of Molecular Biology, vol. 331, no. 4, pp. 829-860, 2003.

[11] M. Y. Galperin and E. V. Koonin, "Divergence and convergence in enzyme evolution," The Journal of Biological Chemistry, vol. 287, no. 1, pp. 21-28, 2012.

[12] K.-F. Wei, L.-J. Wu, J. Chen, Y.-F. Chen, and D.-X. Xie, "Structural evolution and functional diversification analyses of argonaute protein," Journal of Cellular Biochemistry, vol. 113, no. 8, pp. 2576-2585, 2012.

[13] D. E. Almonacid and P. C. Babbitt, "Toward mechanistic classification of enzyme functions," Current Opinion in Chemical Biology, vol. 15, no. 3, pp. 435-442, 2011.

[14] N. Lehman, "RNA in evolution," Wiley Interdisciplinary Reviews: RNA, vol. 1, no. 2, pp. 202-213, 2010.

[15] T. Lan and Y. Lu, "Metal ion-dependent DNAzymes and their applications as biosensors," Metal Ions in Life Sciences, vol. 10, pp. 217-248, 2012.

[16] W. Pan and G. A. Clawson, "Catalytic DNAzymes: derivations and functions," Expert Opinion on Biological Therapy, vol. 8, no. 8, pp. 1071-1085, 2008. 
[17] R. H. Michell, "Evolution of the diverse biological roles of inositols," Biochemical Society Symposia, vol. 74, pp. 223-246, 2007.

[18] R. H. Michell, "Inositol derivatives: evolution and functions," Nature Reviews Molecular Cell Biology, vol. 9, no. 2, pp. 151-161, 2008.

[19] C. Solís-Calero, J. Ortega-Castro, A. Hernández-Laguna, and F. Muñoz, "A comparative DFT study of the Schiff base formation from acetaldehyde and butylamine, glycine and phosphatidylethanolamine," Theoretical Chemistry Accounts, vol. 131, no. 9, pp. 1263-1275, 2012.

[20] C. Solís-Calero, J. Ortega-Castro, and F. Muñoz, "DFT study on amino-phospholipids surface-mediated decomposition of hydrogen peroxide," Journal of Physical Chemistry C, vol. 115, no. 46, pp. 22945-22953, 2011.

[21] M. Yoshimoto, Y. Miyazaki, A. Umemoto, P. Walde, R. Kuboi, and K. Nakao, "Phosphatidylcholine vesicle-mediated decomposition of hydrogen peroxide," Langmuir, vol. 23, no. 18, pp. 9416-9422, 2007.

[22] C. Solís-Calero, J. Ortega-Castro, A. Hernández-Laguna, and F. Muñoz, "A DFT study of the Amadori rearrangement above a phosphatidylethanolamine surface: comparison to reactions in aqueous environment," The Journal of Physical Chemistry C, vol. 117, no. 16, pp. 8299-8309, 2013.

[23] C. Solís-Calero, J. Ortega-Castro, A. Hernández-Laguna, J. Frau, and F. Muñoz, "A DFT study of the carboxymethylphosphatidylethanolamine formation from glyoxal and phosphatidylethanolamine surface. Comparison with the formation of N(c)-(carboxymethyl)lysine from glyoxal and L-lysine," Physical Chemistry Chemical Physics, vol. 17, no. 12, pp. 82108222, 2015.

[24] C. Solís-Calero, J. Ortega-Castro, A. Hernández-Laguna, and F. Muñoz, "DFT study of the mechanism of the reaction of aminoguanidine with methylglyoxal," Journal of Molecular Modeling, vol. 20, no. 4, article 2202, 2014.

[25] R. M. Cordeiro, "Reactive oxygen species at phospholipid bilayers: distribution, mobility and permeation," Biochimica et Biophysica Acta, vol. 1838, no. 1, pp. 438-444, 2014.

[26] H. Khandelia, B. Loubet, A. Olzyńska, P. Jurkiewicz, and M. Hof, "Pairing of cholesterol with oxidized phospholipid species in lipid bilayers," Soft Matter, vol. 10, no. 4, pp. 639-647, 2014.

[27] M. Štefl, R. Šachl, A. Olzyńska et al., "Comprehensive portrait of cholesterol containing oxidized membrane," Biochimica et Biophysica Acta: Biomembranes, vol. 1838, no. 7, pp. 1769-1776, 2014.

[28] E. Conte, F. M. Megli, H. Khandelia, G. Jeschke, and E. Bordignon, "Lipid peroxidation and water penetration in lipid bilayers: a W-band EPR study," Biochimica et Biophysica ActaBiomembranes, vol. 1828, no. 2, pp. 510-517, 2013.

[29] H. Khandelia and O. G. Mouritsen, "Lipid gymnastics: evidence of complete acyl chain reversal in oxidized phospholipids from molecular simulations," Biophysical Journal, vol. 96, no. 7, pp. 2734-2743, 2009.

[30] P. T. Vernier, Z. A. Levine, Y.-H. Wu et al., "Electroporating fields target oxidatively damaged areas in the cell membrane," PLoS ONE, vol. 4, no. 11, Article ID e7966, 2009.

[31] J. Wong-Ekkabut, Z. Xu, W. Triampo, I.-M. Tang, D. P. Tieleman, and L. Monticelli, "Effect of lipid peroxidation on the properties of lipid bilayers: a molecular dynamics study," Biophysical Journal, vol. 93, no. 12, pp. 4225-4236, 2007.
[32] S. Pogodin and V. A. Baulin, "Coarse-grained models of phospholipid membranes within the single chain mean field theory," Soft Matter, vol. 6, no. 10, pp. 2216-2226, 2010.

[33] M. L. Berkowitz, "Detailed molecular dynamics simulations of model biological membranes containing cholesterol," Biochimica et Biophysica Acta, vol. 1788, no. 1, pp. 86-96, 2009.

[34] A. K. Sum, R. Faller, and J. J. de Pablo, "Molecular simulation study of phospholipid bilayers and insights of the interactions with disaccharides," Biophysical Journal, vol. 85, no. 5, pp. 2830 2844, 2003.

[35] H. L. Scott, "Modeling the lipid component of membranes," Current Opinion in Structural Biology, vol. 12, no. 4, pp. 495502, 2002.

[36] K. Sugimori, H. Kawabe, H. Nagao, and K. Nishikawa, "Ab initio and DFT study of ${ }^{31} \mathrm{P}-\mathrm{NMR}$ chemical shifts of sphingomyelin and dihydrosphingomyelin lipid molecule," International Journal of Quantum Chemistry, vol. 109, no. 15, pp. 3685-3693, 2009.

[37] S. Krishnamurty, M. Stefanov, T. Mineva et al., "Density functional theory-based conformational analysis of a phospholipid molecule (dimyristoyl phosphatidylcholine)," Journal of Physical Chemistry B, vol. 112, no. 42, pp. 13433-13442, 2008.

[38] J. A. Snyder and J. D. Madura, "Interaction of the phospholipid head group with representative quartz and aluminosilicate structures: an Ab initio study," Journal of Physical Chemistry B, vol. 112, no. 23, pp. 7095-7103, 2008.

[39] N. C. Hernández and J. F. Sanz, "From periodic DFT calculations to classical molecular dynamics simulations," Computational Materials Science, vol. 35, no. 3, pp. 183-186, 2006.

[40] G. Makov and M. C. Payne, "Periodic boundary conditions in ab initio calculations," Physical Review B, vol. 51, no. 7, pp. 40144022,1995

[41] S. Franzen, "Use of periodic boundary conditions to calculate accurate $\beta$-sheet frequencies using density functional theory," Journal of Physical Chemistry A, vol. 107, no. 46, pp. 9898-9902, 2003.

[42] J. Weng and W. Wang, "Molecular dynamics simulation of membrane proteins," Advances in Experimental Medicine and Biology, vol. 805, pp. 305-329, 2014.

[43] D. P. Tieleman, S. J. Marrink, and H. J. C. Berendsen, "A computer perspective of membranes: molecular dynamics studies of lipid bilayer systems," Biochimica et Biophysica Acta-Reviews on Biomembranes, vol. 1331, no. 3, pp. 235-270, 1997.

[44] P. Jurkiewicz, A. Olzyńska, L. Cwiklik et al., "Biophysics of lipid bilayers containing oxidatively modified phospholipids: insights from fluorescence and EPR experiments and from MD simulations," Biochimica et Biophysica Acta-Biomembranes, vol. 1818, no. 10, pp. 2388-2402, 2012.

[45] J. F. Nagle and S. Tristram-Nagle, "Structure of lipid bilayers," Biochimica et Biophysica Acta-Reviews on Biomembranes, vol. 1469, no. 3, pp. 159-195, 2000.

[46] S. V. Bennun, M. I. Hoopes, C. Xing, and R. Faller, "Coarsegrained modeling of lipids," Chemistry and Physics of Lipids, vol. 159, no. 2, pp. 59-66, 2009.

[47] S. J. Marrink, H. J. Risselada, S. Yefimov, D. P. Tieleman, and A. H. De Vries, "The MARTINI force field: coarse grained model for biomolecular simulations," The Journal of Physical Chemistry B, vol. 111, no. 27, pp. 7812-7824, 2007.

[48] M. G. Saunders and G. A. Voth, "Coarse-graining methods for computational biology," Annual Review of Biophysics, vol. 42, no. 1, pp. 73-93, 2013. 
[49] S. J. Singer and G. L. Nicolson, "The fluid mosaic model of the structure of cell membranes," Science, vol. 175, no. 4023, pp. 720 731, 1972.

[50] M. Langner and K. Kubica, "The electrostatics of lipid surfaces," Chemistry and Physics of Lipids, vol. 101, no. 1, pp. 3-35, 1999.

[51] M. Subramanian, A. Jutila, and P. K. J. Kinnunen, "Binding and dissociation of cytochrome $\mathrm{c}$ to and from membranes containing acidic phospholipids," Biochemistry, vol. 37, no. 5, pp. 1394-1402, 1998.

[52] A. Toker and L. C. Cantley, "Signalling through the lipid products of phosphoinositide-3-OH kinase," Nature, vol. 387, no. 6634, pp. 673-676, 1997.

[53] H. Brockman, "Dipole potential of lipid membranes," Chemistry and Physics of Lipids, vol. 73, no. 1-2, pp. 57-79, 1994.

[54] G. Cevc, "Membrane electrostatics," Biochimica et Biophysica Acta-Biomembranes, vol. 1031, no. 3, pp. 311-382, 1990.

[55] M. C. Wiener and S. H. White, "Fluid bilayer structure determination by the combined use of X-ray and neutron diffraction. I. Fluid bilayer models and the limits of resolution," Biophysical Journal, vol. 59, no. 1, pp. 162-173, 1991.

[56] M. C. Wiener and S. H. White, "Fluid bilayer structure determination by the combined use of X-ray and neutron diffraction. II. 'Composition-space' refinement method," Biophysical Journal, vol. 59, no. 1, pp. 174-185, 1991.

[57] S. H. White and M. C. Wiener, "Determination of the structure of fluid lipid bilayer membranes," in Permeability and Stability of Lipid Bilayers, E. A. Disalvo and S. A. Simon, Eds., pp. 1-19, CRC Press, Boca Raton, Fla, USA, 1995.

[58] M. L. Belaya, M. V. Feigelman, and V. G. Levadny, "Hydration forces as a result of non-local water polarizability," Chemical Physics Letters, vol. 126, no. 3-4, pp. 361-364, 1986.

[59] R. Kjellander and S. Marcelja, "Polarisation of water between molecular surfaces: a molecular dynamics study," Chemica Scripta, vol. 25, pp. 73-80, 1985.

[60] R. Kjellander and S. Marčelja, "Perturbation of hydrogen bonding in water near polar surfaces," Chemical Physics Letters, vol. 120, no. 4-5, pp. 393-396, 1985.

[61] A. Debnath, B. Mukherjee, K. G. Ayappa, P. K. Maiti, and S.-T. Lin, "Entropy and dynamics of water in hydration layers of a bilayer," The Journal of Chemical Physics, vol. 133, no. 17, Article ID 174704, 2010.

[62] V. Lukacova, M. Peng, R. Tandlich, A. Hinderliter, and S. Balaz, "Partitioning of organic compounds in phases imitating the headgroup and core regions of phospholipid bilayers," Langmuir, vol. 22, no. 4, pp. 1869-1874, 2006.

[63] I. Tsogas, D. Tsiourvas, G. Nounesis, and C. M. Paleos, "Interaction of poly-L-arginine with dihexadecyl phosphate/phosphatidylcholine liposomes," Langmuir, vol. 21, no. 13, pp. 5997-6001, 2005.

[64] J. A. Barry and K. Gawrisch, "Direct NMR evidence for ethanol binding to the lipid-water interface of phospholipid bilayers," Biochemistry, vol. 33, no. 26, pp. 8082-8088, 1994.

[65] A. Ortiz, F. J. Aranda, and J. A. Teruel, "Interaction of dirhamnolipid biosurfactants with phospholipid membranes: a molecular level study," Advances in Experimental Medicine and Biology, vol. 672, pp. 42-53, 2010.

[66] G. Da Costa, L. Mouret, S. Chevance, E. Le Rumeur, and A. Bondon, "NMR of molecules interacting with lipids in small unilamellar vesicles," European Biophysics Journal, vol. 36, no. 8, pp. 933-942, 2007.
[67] E. J. Prenner, R. N. A. H. Lewis, and R. N. McElhaney, “The interaction of the antimicrobial peptide gramicidin $\mathrm{S}$ with lipid bilayer model and biological membranes," Biochimica et Biophysica Acta-Biomembranes, vol. 1462, no. 1-2, pp. 201-221, 1999.

[68] A. Y. Mulkidjanian, J. Heberle, and D. A. Cherepanov, "Protons @ interfaces: implications for biological energy conversion," Biochimica et Biophysica Acta: Bioenergetics, vol. 1757, no. 8, pp. 913-930, 2006.

[69] M. Haro, B. Giner, C. Lafuente, M. C. López, F. M. Royo, and P. Cea, "Proton sponge and fatty acid interactions at the air-water interface. Thermodynamic, spectroscopic, and microscopic study," Langmuir, vol. 21, no. 7, pp. 2796-2803, 2005.

[70] P. Ädelroth and P. Brzezinski, "Surface-mediated protontransfer reactions in membrane-bound proteins," Biochimica et Biophysica Acta-Bioenergetics, vol. 1655, no. 1-3, pp. 102-115, 2004.

[71] G. L. Squadrito, E. M. Postlethwait, and S. Matalon, "Elucidating mechanisms of chlorine toxicity: reaction kinetics, thermodynamics, and physiological implications," American Journal of Physiology_Lung Cellular and Molecular Physiology, vol. 299, no. 3, pp. L289-L300, 2010.

[72] R. Zamora and F. J. Hidalgo, "Phosphatidylethanolamine modification by oxidative stress product 4,5(E)-epoxy-2(E)heptenal," Chemical Research in Toxicology, vol. 16, no. 12, pp. 1632-1641, 2003.

[73] B. Vilanova, J. M. Gallardo, C. Caldés et al., "Formation of Schiff bases of O-phosphorylethanolamine and O-phosphod, l-serine with pyridoxal $5^{\prime}$-phosphate. Experimental and theoretical studies," Journal of Physical Chemistry A, vol. 116, no. 8, pp. 1897-1905, 2012.

[74] C. Caldés, B. Vilanova, M. Adrover, F. Muñoz, and J. Donoso, "Understanding non-enzymatic aminophospholipid glycation and its inhibition. Polar head features affect the kinetics of Schiff base formation," Bioorganic and Medicinal Chemistry, vol. 19, no. 15, pp. 4536-4543, 2011.

[75] E. Wachtel, D. Bach, R. F. Epand, A. Tishbee, and R. M. Epand, "A product of ozonolysis of cholesterol alters the biophysical properties of phosphatidylethanolamine membranes," Biochemistry, vol. 45, no. 4, pp. 1345-1351, 2006.

[76] M. Yoshimoto, Y. Miyazaki, M. Sato, K. Fukunaga, R. Kuboi, and K. Nakao, "Mechanism for high stability of liposomal glucose oxidase to inhibitor hydrogen peroxide produced in prolonged glucose oxidation," Bioconjugate Chemistry, vol. 15, no. 5, pp. 1055-1061, 2004.

[77] C. Solís-Calero, J. Ortega-Castro, and F. Muñoz, "Reactivity of a phospholipid monolayer model under periodic boundary conditions: a density functional theory study of the schiff base formation between phosphatidylethanolamine and acetaldehyde," Journal of Physical Chemistry B, vol. 114, no. 48, pp. 1587915885, 2010.

[78] E. Schnitzer, I. Pinchuk, and D. Lichtenberg, "Peroxidation of liposomal lipids," European Biophysics Journal, vol. 36, no. 4-5, pp. 499-515, 2007.

[79] A. M. Bouchet, M. A. Frías, F. Lairion et al., "Structural and dynamical surface properties of phosphatidylethanolamine containing membranes," Biochimica et Biophysica Acta, vol. 1788, no. 5, pp. 918-925, 2009.

[80] M. Rao, J. Eichberg, and J. Oró, "Synthesis of phosphatidylethanolamine under possible primitive earth conditions," Journal of Molecular Evolution, vol. 25, no. 1, pp. 1-6, 1987. 
[81] E. Hokazono, H. Tamezane, T. Hotta, Y. Kayamori, and S. Osawa, "Enzymatic assay of phosphatidylethanolamine in serum using amine oxidase from Arthrobacter sp," Clinica Chimica Acta, vol. 412, no. 15-16, pp. 1436-1440, 2011.

[82] Y. Zhang, X. Wang, Z. Xiang et al., "Promotion of cellular migration and apoptosis resistance by a mouse eyespecific phosphatidylethanolamine-binding protein," International Journal of Molecular Medicine, vol. 19, no. 1, pp. 55-63, 2007.

[83] L. A. Falls, B. Furie, and B. C. Furie, "Role of phosphatidylethanolamine in assembly and function of the factor IXa-factor VIIIa complex on membrane surfaces," Biochemistry, vol. 39, no. 43, pp. 13216-13222, 2000.

[84] A. Signorell, J. Jelk, M. Rauch, and P. Bütikofer, "Phosphatidylethanolamine is the precursor of the ethanolamine phosphoglycerol moiety bound to eukaryotic elongation factor 1A," The Journal of Biological Chemistry, vol. 283, no. 29, pp. 20320-20329, 2008.

[85] A. K. Menon and V. L. Stevens, "Phosphatidylethanolamine is the donor of the ethanolamine residue linking a glycosylphosphatidylinositol anchor to protein," The Journal of Biological Chemistry, vol. 267, no. 22, pp. 15277-15280, 1992.

[86] O. Higuchi, K. Nakagawa, T. Tsuzuki, T. Suzuki, S. Oikawa, and T. Miyazawa, "Aminophospholipid glycation and its inhibitor screening system: a new role of pyridoxal $5^{\prime}$-phosphate as the inhibitor," Journal of Lipid Research, vol. 47, no. 5, pp. 964-974, 2006.

[87] A. Mulgrew-Nesbitt, K. Diraviyam, J. Wang et al., "The role of electrostatics in protein-membrane interactions," Biochimica et Biophysica Acta-Molecular and Cell Biology of Lipids, vol. 1761, no. 8, pp. 812-826, 2006.

[88] A. Zachowski, "Phospholipids in animal eukaryotic membranes: transverse asymmetry and movement," Biochemical Journal, vol. 294, no. 1, pp. 1-14, 1993.

[89] K. Asano, M. Miwa, K. Miwa et al., "Masking of phosphatidylserine inhibits apoptotic cell engulfment and induces autoantibody production in mice," The Journal of Experimental Medicine, vol. 200, no. 4, pp. 459-467, 2004.

[90] B. Verhoven, R. A. Schlegel, and P. Williamson, "Mechanisms of phosphatidylserine exposure, a phagocyte recognition signal, on apoptotic T lymphocytes," Journal of Experimental Medicine, vol. 182, no. 5, pp. 1597-1601, 1995.

[91] E. Maciel, R. N. Da Silva, C. Simões et al., "Liquid chromatography-tandem mass spectrometry of phosphatidylserine advanced glycated end products," Chemistry and Physics of Lipids, vol. 174, pp. 1-7, 2013.

[92] Y. Wang, W. Beck, R. Deppisch, S. M. Marshall, N. A. Hoenich, and M. G. Thompson, "Advanced glycation end products elicit externalization of phosphatidylserine in a subpopulation of platelets via $5-\mathrm{HT}_{2 \mathrm{~A} / 2 \mathrm{C}}$ receptors," American Journal of Physiology-Cell Physiology, vol. 293, no. 1, pp. C328-C336, 2007.

[93] J. E. Vance and G. Tasseva, "Formation and function of phosphatidylserine and phosphatidylethanolamine in mammalian cells," Biochimica et Biophysica Acta: Molecular and Cell Biology of Lipids, vol. 1831, no. 3, pp. 543-554, 2013.

[94] T. Yeung, G. E. Gilbert, J. Shi, J. Silvius, A. Kapus, and S. Grinstein, "Membrane phosphatidylserine regulates surface charge and protein localization," Science, vol. 319, no. 5860, pp. 210-213, 2008.

[95] T. Yeung, B. Heit, J.-F. Dubuisson et al., "Contribution of phosphatidylserine to membrane surface charge and protein targeting during phagosome maturation," The Journal of Cell Biology, vol. 185, no. 5, pp. 917-928, 2009.

[96] C. T. Sigal, W. Zhou, C. A. Buser, S. McLaughlin, and M. D. Resh, "Amino-terminal basic residues of Src mediate membrane binding through electrostatic interaction with acidic phospholipids," Proceedings of the National Academy of Sciences of the United States of America, vol. 91, no. 25, pp. 12253-12257, 1994.

[97] Z. Li, L. B. Agellon, and D. E. Vance, "Phosphatidylcholine homeostasis and liver failure," The Journal of Biological Chemistry, vol. 280, no. 45, pp. 37798-37802, 2005.

[98] K. V. Damodaran, K. M. Merz Jr., and B. P. Gaber, "Structure and dynamics of the dilauroylphosphatidylethanolamine lipid bilayer," Biochemistry®, vol. 31, no. 33, pp. 7656-7664, 1992.

[99] K. V. Damodaran and K. M. Merz Jr., "A comparison of DMPCand DLPE-based lipid bilayers," Biophysical Journal, vol. 66, no. 4, pp. 1076-1087, 1994.

[100] M. J. Dougherty and F. H. Arnold, "Directed evolution: new parts and optimized function," Current Opinion in Biotechnology, vol. 20, no. 4, pp. 486-491, 2009.

[101] R. P. Richter, J. L. K. Him, and A. Brisson, "Supported lipid membranes," Materials Today, vol. 6, no. 11, pp. 32-37, 2003.

[102] S. Biswas, N. S. Dodwadkar, P. P. Deshpande, and V. P. Torchilin, "Liposomes loaded with paclitaxel and modified with novel triphenylphosphonium-PEG-PE conjugate possess low toxicity, target mitochondria and demonstrate enhanced antitumor effects in vitro and in vivo," Journal of Controlled Release, vol. 159, no. 3, pp. 393-402, 2012.

[103] M. Sánchez, F. J. Aranda, J. A. Teruel, and A. Ortiz, "New pHsensitive liposomes containing phosphatidylethanolamine and a bacterial dirhamnolipid," Chemistry and Physics of Lipids, vol. 164, no. 1, pp. 16-23, 2011.

[104] D. C. Drummond, M. Zignani, and J.-C. Leroux, "Current status of pH-sensitive liposomes in drug delivery," Progress in Lipid Research, vol. 39, no. 5, pp. 409-460, 2000.

[105] H. Karanth and R. S. R. Murthy, "pH-sensitive liposomesprinciple and application in cancer therapy," Journal of Pharmacy and Pharmacology, vol. 59, no. 4, pp. 469-483, 2007.

[106] J. Wang, Y. Wang, and W. Liang, "Delivery of drugs to cell membranes by encapsulation in PEG-PE micelles," Journal of Controlled Release, vol. 160, no. 3, pp. 637-651, 2012.

[107] R. R. Sawant and V. P. Torchilin, "Polymeric micelles: polyethylene glycol-phosphatidylethanolamine (PEG-PE)based micelles as an example," Methods in Molecular Biology, vol. 624, pp. 131-149, 2010.

[108] L. Mu, T. A. Elbayoumi, and V. P. Torchilin, "Mixed micelles made of poly(ethylene glycol)-phosphatidylethanolamine conjugate and D- $\alpha$-tocopheryl polyethylene glycol 1000 succinate as pharmaceutical nanocarriers for camptothecin," International Journal of Pharmaceutics, vol. 306, no. 1-2, pp. 142-149, 2005.

[109] B. Halliwell and J. Gutteridge, Free Radicals in Biology and Medicine, Oxford University Press, 4th edition, 2007.

[110] W. Dröge, "Free radicals in the physiological control of cell function," Physiological Reviews, vol. 82, no. 1, pp. 47-95, 2002.

[111] D. Ivanova, R. Bakalova, D. Lazarova, V. Gadjeva, and Z. Zhelev, "The impact of reactive oxygen species on anticancer therapeutic strategies," Advances in Clinical and Experimental Medicine, vol. 22, no. 6, pp. 899-908, 2013.

[112] A. Reis and C. M. Spickett, "Chemistry of phospholipid oxidation," Biochimica et Biophysica Acta, vol. 1818, no. 10, pp. 23742387, 2012. 
[113] R. Pamplona, "Advanced lipoxidation end-products," ChemicoBiological Interactions, vol. 192, no. 1-2, pp. 14-20, 2011.

[114] R. Battino, T. R. Rettich, and T. Tominaga, "The solubility of oxygen and ozone in liquids," Journal of Physical and Chemical Reference Data, vol. 12, no. 2, pp. 163-178, 1983.

[115] X. Liu, M. J. S. Miller, M. S. Joshi, D. D. Thomas, and J. R. Lancaster Jr., "Accelerated reaction of nitric oxide with $\mathrm{O}_{2}$ within the hydrophobic interior of biological membranes," Proceedings of the National Academy of Sciences of the United States of America, vol. 95, no. 5, pp. 2175-2179, 1998.

[116] E. Codorniu-Hernández and P. G. Kusalik, "Mobility mechanism of hydroxyl radicals in aqueous solution via hydrogen transfer," Journal of the American Chemical Society, vol. 134, no. 1, pp. 532-538, 2012.

[117] A. Catalá, "An overview of lipid peroxidation with emphasis in outer segments of photoreceptors and the chemiluminescence assay," The International Journal of Biochemistry and Cell Biology, vol. 38, no. 9, pp. 1482-1495, 2006.

[118] S. E. Norris, T. W. Mitchell, and P. L. Else, "Phospholipid peroxidation: lack of effect of fatty acid pairing," Lipids, vol. 47, no. 5, pp. 451-460, 2012.

[119] A. Catalá, "Lipid peroxidation of membrane phospholipids generates hydroxy-alkenals and oxidized phospholipids active in physiological and/or pathological conditions," Chemistry and Physics of Lipids, vol. 157, no. 1, pp. 1-11, 2009.

[120] G. R. Buettner, "The pecking order of free radicals and antioxidants: lipid peroxidation, $\alpha$-tocopherol, and ascorbate," Archives of Biochemistry and Biophysics, vol. 300, no. 2, pp. 535-543, 1993.

[121] S. H. Lee, T. Oe, and I. A. Blair, "Vitamin C-induced decomposition of lipid hydroperoxides to endogenous genotoxins," Science, vol. 292, no. 5524, pp. 2083-2086, 2001.

[122] A. Negre-Salvayre, C. Coatrieux, C. Ingueneau, and R. Salvayre, "Advanced lipid peroxidation end products in oxidative damage to proteins. Potential role in diseases and therapeutic prospects for the inhibitors," British Journal of Pharmacology, vol. 153, no. 1, pp. 6-20, 2008.

[123] S. K. Jain, "The accumulation of malonyldialdehyde, a product of fatty acid peroxidation, can disturb aminophospholipid organization in the membrane bilayer of human erythrocytes," The Journal of Biological Chemistry, vol. 259, no. 6, pp. 33913394, 1984.

[124] J. A. Imlay, "Cellular defenses against superoxide and hydrogen peroxide," Annual Review of Biochemistry, vol. 77, pp. 755-776, 2008.

[125] M. V. Avshalumov, D. G. MacGregor, L. M. Sehgal, and M. E. Rice, "The glial antioxidant network and neuronal ascorbate: protective yet permissive for $\mathrm{H}_{2} \mathrm{O}_{2}$ signaling," Neuron Glia Biology, vol. 1, no. 04, p. 365, 2004.

[126] O. Baud, A. E. Greene, J. Li, H. Wang, J. J. Volpe, and P. A. Rosenberg, "Glutathione peroxidase-catalase cooperativity is required for resistance to hydrogen peroxide by mature rat oligodendrocytes," The Journal of Neuroscience, vol. 24, no. 7, pp. 1531-1540, 2004.

[127] C. W. Olanow, "A rationale for monoamine oxidase inhibition as neuroprotective therapy for Parkinson's disease," Movement Disorders, vol. 8, no. 1, pp. S1-S7, 1993.

[128] H. Sies, "Role of metabolic $\mathrm{H}_{2} \mathrm{O}_{2}$ generation: redox signaling and oxidative stress," The Journal of Biological Chemistry, vol. 289, no. 13, pp. 8735-8741, 2014.

[129] H. J. Forman, "Reactive oxygen species and $\alpha, \beta$-unsaturated aldehydes as second messengers in signal transduction," Annals of the New York Academy of Sciences, vol. 1203, pp. 35-44, 2010.
[130] L. Domínguez, A. Sosa-Peinado, and W. Hansberg, "Catalase evolved to concentrate $\mathrm{H}_{2} \mathrm{O}_{2}$ at its active site," Archives of Biochemistry and Biophysics, vol. 500, no. 1, pp. 82-91, 2010.

[131] G. Groeger, C. Quiney, and T. G. Cotter, "Hydrogen peroxide as a cell-survival signaling molecule," Antioxidants and Redox Signaling, vol. 11, no. 11, pp. 2655-2671, 2009.

[132] E. A. Veal, A. M. Day, and B. A. Morgan, "Hydrogen peroxide sensing and signaling," Molecular Cell, vol. 26, no. 1, pp. 1-14, 2007.

[133] H. M. Semchyshyn, "Reactive carbonyl species in vivo: generation and dual biological effects," The Scientific World Journal, vol. 2014, Article ID 417842, 10 pages, 2014.

[134] P. Zimniak, "Relationship of electrophilic stress to aging," Free Radical Biology and Medicine, vol. 51, no. 6, pp. 1087-1105, 2011.

[135] R. J. Schaur, "Basic aspects of the biochemical reactivity of 4hydroxynonenal," Molecular Aspects of Medicine, vol. 24, no. 45, pp. 149-159, 2003.

[136] R. Pamplona, "Membrane phospholipids, lipoxidative damage and molecular integrity: a causal role in aging and longevity," Biochimica et Biophysica Acta, vol. 1777, no. 10, pp. 1249-1262, 2008.

[137] M. Guichardant, N. Bernoud-Hubac, B. Chantegrel, C. Deshayes, and M. Lagarde, "Aldehydes from n-6 fatty acid peroxidation. Effects on aminophospholipids," Prostaglandins Leukotrienes and Essential Fatty Acids, vol. 67, no. 2-3, pp. 147-149, 2002.

[138] M. Guichardant, P. Taibi-Tronche, L. B. Fay, and M. Lagarde, "Covalent modifications of aminophospholipids by 4hydroxynonenal," Free Radical Biology and Medicine, vol. 25, no. 9, pp. 1049-1056, 1998.

[139] G. Poli and R. J. Schaur, "4-Hydroxynonenal in the pathomechanisms of oxidative stress," IUBMB Life, vol. 50, no. 4-5, pp. 315-321, 2000.

[140] N. Bernoud-Hubac, L. B. Fay, V. Armarnath et al., "Covalent binding of isoketals to ethanolamine phospholipids," Free Radical Biology and Medicine, vol. 37, no. 10, pp. 1604-1611, 2004.

[141] G. Vistoli, D. De Maddis, A. Cipak, N. Zarkovic, M. Carini, and G. Aldini, "Advanced glycoxidation and lipoxidation end products (AGEs and ALEs): an overview of their mechanisms of formation," Free Radical Research, vol. 47, no. 1, pp. 3-27, 2013.

[142] Y. Wang and C.-T. Ho, "Flavour chemistry of methylglyoxal and glyoxal," Chemical Society Reviews, vol. 41, no. 11, pp. 4140-4149, 2012.

[143] Z. Turk, "Glycotoxines, carbonyl stress and relevance to diabetes and its complications," Physiological Research, vol. 59, no. 2, pp. 147-156, 2010.

[144] T. Miyazawa, K. Nakagawa, S. Shimasaki, and R. Nagai, "Lipid glycation and protein glycation in diabetes and atherosclerosis," Amino Acids, vol. 42, no. 4, pp. 1163-1170, 2012.

[145] N. Shoji, K. Nakagawa, A. Asai et al., "LC-MS/MS analysis of carboxymethylated and carboxyethylated phosphatidylethanolamines in human erythrocytes and blood plasma," Journal of Lipid Research, vol. 51, no. 8, pp. 2445-2453, 2010.

[146] R. Pamplona, J. R. Requena, M. Portero-Otín, J. Prat, S. R. Thorpe, and M. J. Bellmunt, "Carboxymethylated phosphatidylethanolamine in mitochondrial membranes of mammals. Evidence for intracellular lipid glycoxidation," European Journal of Biochemistry, vol. 255, no. 3, pp. 685-689, 1998.

[147] J. R. Requena, M. U. Ahmed, C. W. Fountain et al., "Carboxymethylethanolamine, a biomarker of phospholipid modification during the Maillard reaction in vivo," The Journal of Biological Chemistry, vol. 272, no. 28, pp. 17473-17479, 1997. 
[148] R. Nagai, K. Ikeda, Y. Kawasaki et al., "Conversion of Amadori product of Maillard reaction to $\mathrm{N}(\varepsilon)$-(carboxymethyl)lysine in alkaline condition," FEBS Letters, vol. 425, no. 2, pp. 355-360, 1998.

[149] P. J. Thornalley, "Protein and nucleotide damage by glyoxal and methylglyoxal in physiological systems - role in ageing and disease," Drug Metabolism and Drug Interactions, vol. 23, no. 1-2, pp. 125-150, 2008.

[150] C. M. Utzmann and M. O. Lederer, "Identification and quantification of aminophospholipid-linked Maillard compounds in model systems and egg yolk products," Journal of Agricultural and Food Chemistry, vol. 48, no. 4, pp. 1000-1008, 2000.

[151] M. O. Lederer and M. Baumann, "Formation of a phospholipidlinked pyrrolecarbaldehyde from model reactions of D-glucose and 3-deoxyglucosone with phosphatidyl ethanolamine," Bioorganic and Medicinal Chemistry, vol. 8, no. 1, pp. 115-121, 2000.

[152] V. Levi, A. M. Villamil Giraldo, P. R. Castello, J. P. F. C. Rossi, and F. L. González Flecha, "Effects of phosphatidylethanolamine glycation on lipid-protein interactions and membrane protein thermal stability," Biochemical Journal, vol. 416, no. 1, pp. 145$152,2008$.

[153] E. Doria, D. Buonocore, A. Focarelli, and F. Marzatico, "Relationship between human aging muscle and oxidative system pathway," Oxidative Medicine and Cellular Longevity, vol. 2012, Article ID 830257, 13 pages, 2012.

[154] P. Voss and W. Siems, "Clinical oxidation parameters of aging," Free Radical Research, vol. 40, no. 12, pp. 1339-1349, 2006.

[155] K. Nowotny, T. Jung, T. Grune, and A. Höhn, "Accumulation of modified proteins and aggregate formation in aging," Experimental Gerontology, vol. 59, pp. 3-12, 2014.

[156] T. Grune and K. J. A. Davies, "The proteasomal system and HNE-modified proteins," Molecular Aspects of Medicine, vol. 24, no. 4-5, pp. 195-204, 2003.

[157] B. H. Toyama and M. W. Hetzer, "Protein homeostasis: live long, won't prosper," Nature Reviews Molecular Cell Biology, vol. 14, no. 1, pp. 55-61, 2013.

[158] E. Eden, N. Geva-Zatorsky, I. Issaeva et al., "Proteome half-life dynamics in living human cells," Science, vol. 331, no. 6018, pp. 764-768, 2011.

[159] A. J. Hulbert, R. Pamplona, R. Buffenstein, and W. A. Buttemer, "Life and death: metabolic rate, membrane composition, and life span of animals," Physiological Reviews, vol. 87, no. 4, pp. 1175-1213, 2007.

[160] R. F. Krause and K. C. Beamer, "Apparent turnover of subcellular phospholipids in the liver of control and vitamin A-deficient rats," Journal of Nutrition, vol. 102, no. 11, pp. 1465-1469, 1972.

[161] L. Freysz, R. Bieth, and P. Mandel, "Kinetics of the biosynthesis of phospholipids in neurons and glial cells isolated from rat brain cortex," Journal of Neurochemistry, vol. 16, no. 10, pp. 14171424, 1969.

[162] J. C. DeMar Jr., K. Ma, J. M. Bell, and S. I. Rapoport, "Halflives of docosahexaenoic acid in rat brain phospholipids are prolonged by 15 weeks of nutritional deprivation of $n-3$ polyunsaturated fatty acids," Journal of Neurochemistry, vol. 91, no. 5, pp. 1125-1137, 2004.

[163] J. T.Green, Z. Liu, and R. P. Bazinet, "Brain phospholipid arachidonic acid half-lives are not altered following 15 weeks of N-3 polyunsaturated fatty acid adequate or deprived diet," The Journal of Lipid Research, vol. 51, no. 3, pp. 535-543, 2010.

[164] C. Ott, K. Jacobs, E. Haucke, A. Navarrete Santos, T. Grune, and A. Simm, "Role of advanced glycation end products in cellular signaling," Redox Biology, vol. 2, no. 1, pp. 411-429, 2014.
[165] V. M. Monnier, "Intervention against the Maillard reaction in vivo," Archives of Biochemistry and Biophysics, vol. 419, no. 1, pp. 1-15, 2003.

[166] R. Singh, A. Barden, T. Mori, and L. Beilin, "Advanced glycation end-products: a review," Diabetologia, vol. 44, no. 2, pp. 129-146, 2001.

[167] M. Namiki and T. Hayashi, "A new mechanism of the Maillard reaction involving sugar fragmentation and free radical formation," ACS Symposium Series, vol. 215, pp. 21-46, 1983.

[168] S. P. Wolff and R. T. Dean, "Glucose autoxidation and protein modification. The potential role of 'utoxidative glycosylation' in diabetes," Biochemical Journal, vol. 245, no. 1, pp. 243-250, 1987.

[169] R. Casasnovas, M. Adrover, J. Ortega-Castro, J. Frau, J. Donoso, and F. Muñoz, "C-H activation in pyridoxal-5/-phosphate Schiff bases: the role of the imine nitrogen. A combined experimental and computational study," The Journal of Physical Chemistry B, vol. 116, no. 35, pp. 10665-10675, 2012.

[170] R. Casasnovas, J. Frau, J. Ortega-Castro, J. Donoso, and F. Muñoz, "C-H activation in pyridoxal-5'-phosphate and pyridoxamine- $5^{\prime}$ - phosphate schiff bases: effect of metal chelation. A computational study," The Journal of Physical Chemistry $B$, vol. 117, no. 8, pp. 2339-2347, 2013.

[171] J. Ortega-Castro, M. Adrover, J. Frau, A. Salvà, J. Donoso, and F. Muñoz, "DFT studies on schiff base formation of vitamin B6 analogues. Reaction between a pyridoxamine-Analogue and carbonyl compounds," The Journal of Physical Chemistry A, vol. 114, no. 13, pp. 4634-4640, 2010.

[172] A. Salvà, J. Donoso, J. Frau, and F. Muñoz, "DFT studies on schiff base formation of vitamin $\mathrm{B}_{6}$ analogues," The Journal of Physical Chemistry A, vol. 107, no. 44, pp. 9409-9414, 2003.

[173] D. K. Hincha and M. Hagemann, "Stabilization of model membranes during drying by compatible solutes involved in the stress tolerance of plants and microorganisms," Biochemical Journal, vol. 383, no. 2, pp. 277-283, 2004.

[174] M. Del C. Luzardo, F. Amalfa, A. M. Nuñez, S. Díaz, A. C. Biondi De Lopez, and E. A. Disalvo, "Effect of trehalose and sucrose on the hydration and dipole potential of lipid bilayers," Biophysical Journal, vol. 78, no. 5, pp. 2452-2458, 2000.

[175] N. M. Tsvetkova, B. L. Phillips, L. M. Crowe, J. H. Crowe, and S. H. Risbud, "Effect of sugars on headgroup mobility in freezedried dipalmitoylphosphatidylcholine bilayers: solid-state 31P NMR and FTIR studies," Biophysical Journal, vol. 75, no. 6, pp. 2947-2955, 1998.

[176] C. S. Pereira and P. H. Hünenberger, "Interaction of the sugars trehalose, maltose and glucose with a phospholipid bilayer: a comparative molecular dynamics study," Journal of Physical Chemistry B, vol. 110, no. 31, pp. 15572-15581, 2006.

[177] R. Ramasamy, S. F. Yan, and A. M. Schmidt, "Receptor for AGE (RAGE): signaling mechanisms in the pathogenesis of diabetes and its complications," Annals of the New York Academy of Sciences, vol. 1243, no. 1, pp. 88-102, 2011.

[178] A. E. N. Ferreira, A. M. J. Ponces Freire, and E. O. Voit, "A quantitative model of the generation of $\mathrm{N} \varepsilon$-(carboxymethyl)lysine in the Maillard reaction between collagen and glucose," Biochemical Journal, vol. 376, no. 1, pp. 109-121, 2003.

[179] N. M. J. Hanssen, L. Engelen, I. Ferreira et al., "Plasma levels of advanced glycation endproducts $N^{\epsilon}$-(carboxymethyl)lysine, $N^{\epsilon}$-(carboxyethyl)lysine, and pentosidine are not independently associated with cardiovascular disease in individuals with or without type 2 diabetes: The Hoorn and CODAM studies," The Journal of Clinical Endocrinology and Metabolism, vol. 98, no. 8, pp. E1369-E1373, 2013. 
[180] I. Roncero-Ramos, C. Delgado-Andrade, F. J. Tessier et al., "Metabolic transit of $N^{\varepsilon}$-carboxymethyl-lysine after consumption of AGEs from bread crust," Food \& Function, vol. 4, no. 7, pp. 1032-1039, 2013.

[181] R. Nagai, K. Ikeda, T. Higashi et al., "Hydroxyl radical mediates $\mathrm{N}(\varepsilon)$-(carboxymethyl)lysine formation from Amadori product," Biochemical and Biophysical Research Communications, vol. 234, no. 1, pp. 167-172, 1997.

[182] M. U. Ahmed, S. R. Thorpe, and J. W. Baynes, "Identification of $\mathrm{N}(\varepsilon)$-carboxymethyllysine as a degradation product of fructoselysine in glycated protein," Journal of Biological Chemistry, vol. 261, no. 11, pp. 4889-4894, 1986.

[183] Y. Al-Abed and R. Bucala, " $\mathrm{N}^{\varepsilon}$-carboxymethyllysine formation by direct addition of glyoxal to lysine during the Maillard reaction," Bioorganic and Medicinal Chemistry Letters, vol. 5, no. 18, pp. 2161-2162, 1995.

[184] K. J. Wells-Knecht, D. V. Zyzak, J. E. Litchfield, S. R. Thorpe, and J. W. Baynes, "Mechanism of autoxidative glycosylation: identification of glyoxal and arabinose as intermediates in the autoxidative modification of proteins by glucose," Biochemistry, vol. 34, no. 11, pp. 3702-3709, 1995.

[185] M. A. Glomb and V. M. Monnier, "Mechanism of protein modification by glyoxal and glycolaldehyde, reactive intermediates of the Maillard reaction," The Journal of Biological Chemistry, vol. 270, no. 17, pp. 10017-10026, 1995.

[186] F. J. Hidalgo and R. Zamora, "Interplay between the Maillard reaction and lipid peroxidation in biochemical systems," Annals of the New York Academy of Sciences, vol. 1043, pp. 319-326, 2005. 


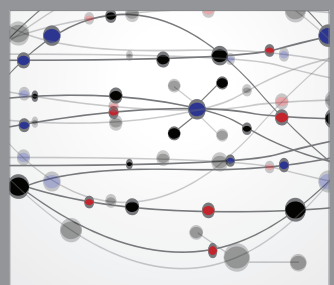

The Scientific World Journal
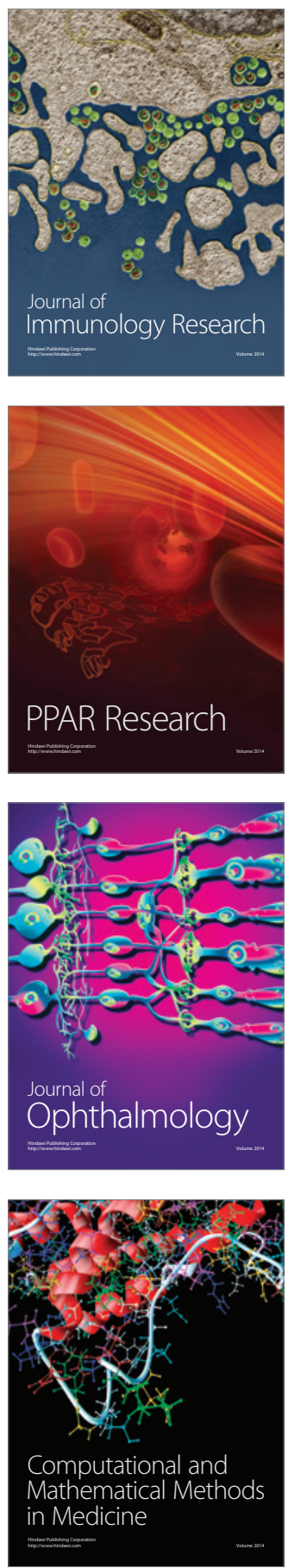

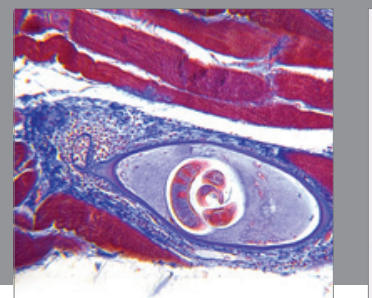

Gastroenterology

Research and Practice
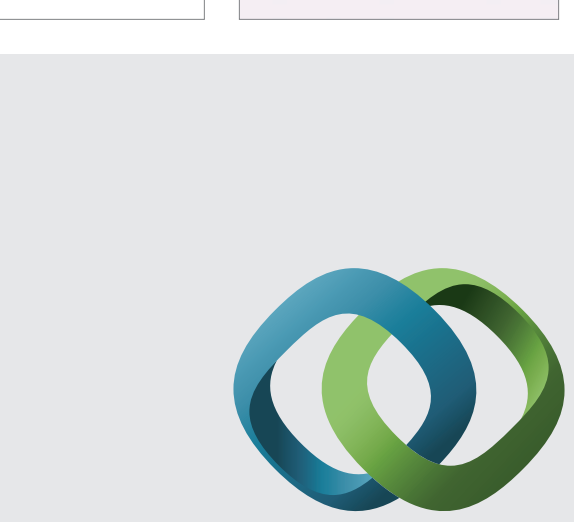

\section{Hindawi}

Submit your manuscripts at

http://www.hindawi.com
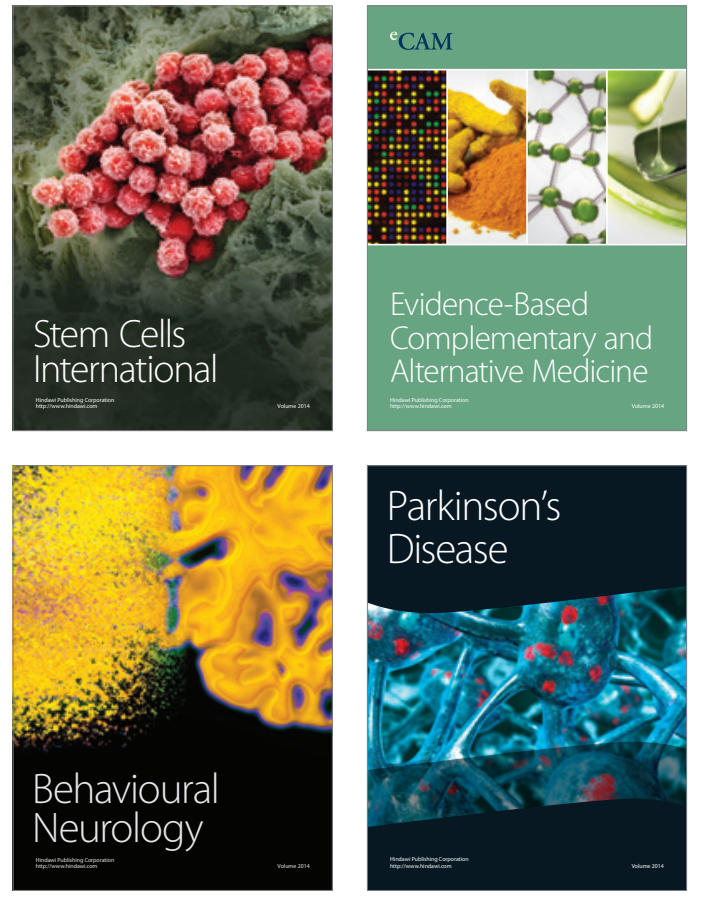
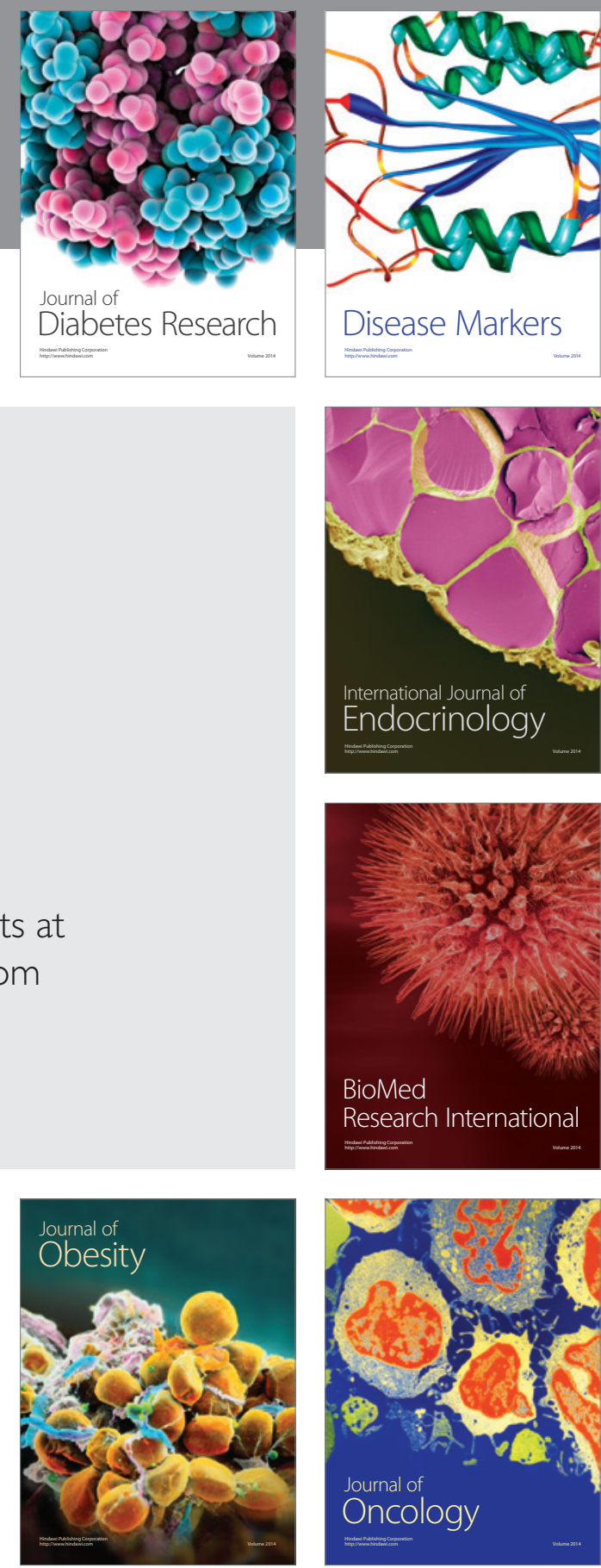

Disease Markers
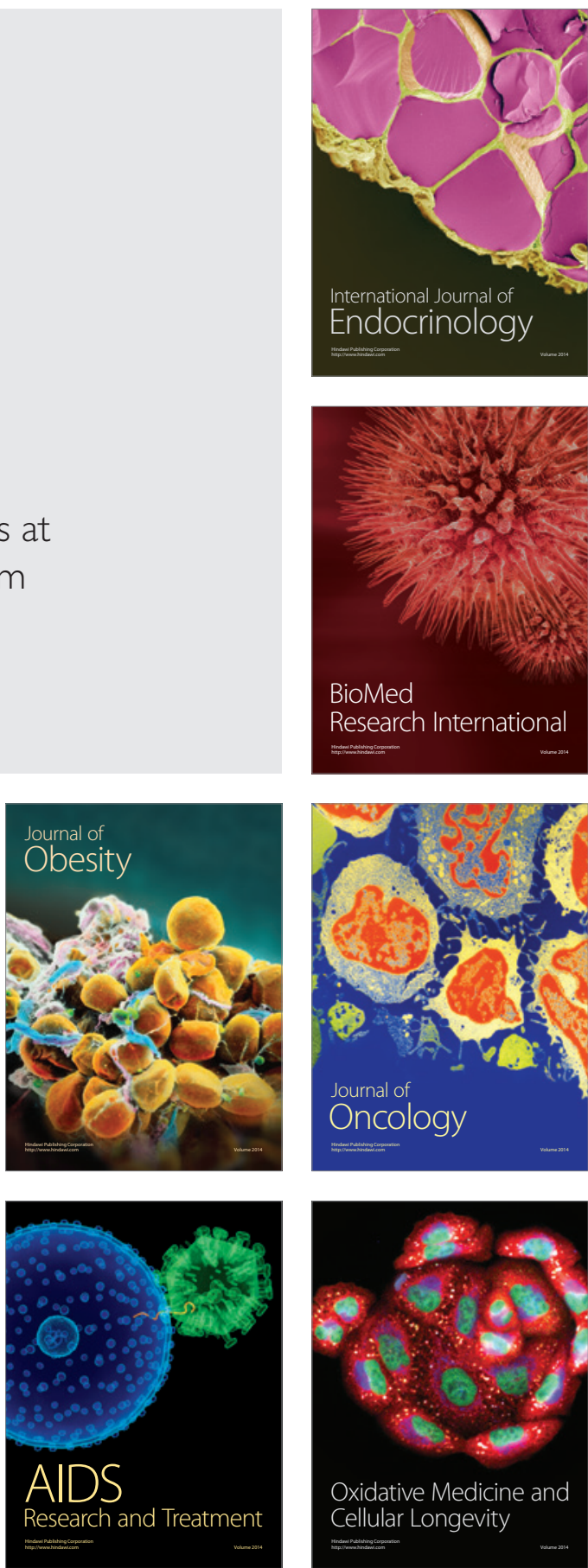